OPEN ACCESS

Edited by:

Oliver Stork,

Universitätsklinikum Magdeburg,

Germany

Reviewed by:

Mart Saarma,

University of Helsinki, Finland

Ralf Kleene,

Universitätsklinikum

Hamburg-Eppendorf, Germany

*Correspondence:

Mirolyuba llieva

milieva@health.sdu.dk

Received: 06 June 2018 Accepted: 07 February 2019

Published: 22 February 2019

Citation:

Ilieva M, Nielsen J, Korshunova I,

Gotfryd K, Bock E, Pankratova S and Michel TM (2019) Artemin and an Artemin-Derived Peptide, Artefin, Induce Neuronal Survival, and Differentiation Through Ret and NCAM

Front. Mol. Neurosci. 12:47. doi: 10.3389/fnmol.2019.00047

\section{Artemin and an Artemin-Derived Peptide, Artefin, Induce Neuronal Survival, and Differentiation Through Ret and NCAM}

\author{
Mirolyuba llieva ${ }^{1,2,3,4 *}$, Janne Nielsen ${ }^{3}$, Irina Korshunova ${ }^{3}, K^{2}$ amil Gotfryd ${ }^{3}$, \\ Elisabeth Bock ${ }^{3}$, Stanislava Pankratova ${ }^{3,5}$ and Tanja Maria Michel1,2,4 \\ ${ }^{1}$ Department of Psychiatry, Department of Clinical Research, University of Southern Denmark, Odense, Denmark, \\ ${ }^{2}$ Psychiatry in the Region of Southern Denmark, Odense University Hospital, Odense, Denmark, ${ }^{3}$ Laboratory of Neural \\ Plasticity, Department of Neuroscience, University of Copenhagen, Copenhagen, Denmark, ${ }^{4}$ Brain Research - \\ Inter-Disciplinary Guided Excellence, Department of Clinical Research, University of Southern Denmark, Odense, Denmark, \\ ${ }^{5}$ Research Laboratory for Stereology and Neuroscience, Bispebjerg-Frederiksberg Hospital, Copenhagen University \\ Hospital, Copenhagen, Denmark
}

Artemin (ARTN) is a neurotrophic factor from the GDNF family ligands (GFLs) that is involved in development of the nervous system and neuronal differentiation and survival. ARTN signals through a complex receptor system consisting of the RET receptor tyrosine kinase and a glycosylphosphatidylinositol-anchored co-receptor GFL receptor $\alpha$, GFR $\alpha 3$. We found that ARTN binds directly to neural cell adhesion molecule (NCAM) and that ARTN-induced neuritogenesis requires NCAM expression and activation of NCAM-associated signaling partners, thus corroborating that NCAM is an alternative receptor for ARTN. We designed a small peptide, artefin, that could interact with GFR $\alpha 3$ and demonstrated that this peptide agonist induces RET phosphorylation and mimics the biological functions of ARTN - neuroprotection and neurite outgrowth. Moreover, artefin mimicked the binding of ARTN to NCAM and required NCAM expression and activation for its neurite elongation effect, thereby suggesting that artefin represents a binding site for NCAM within ARTN. We showed that biological effects of ARTN and artefin can be inhibited by abrogation of both NCAM and RET, suggesting a more complex signaling mechanism that previously thought. As NCAM plays a significant role in neurodevelopment, regeneration, and synaptic plasticity we suggest that ARTN and its mimetics are promising candidates for treatment of neurological disorders and warrant further investigations.

Keywords: artemin, mimetic peptides, NCAM, neuroprotection, neurite outgrowth

\section{INTRODUCTION}

Neurotrophic factors play an essential role in the survival, differentiation, and maintenance of neurons in the central and peripheral nervous systems (Anders et al., 2001; Enomoto et al., 2001; Honma et al., 2002). Their discovery and characterization have been instrumental for the understanding of the development, plasticity, and repair of the nervous system (Baloh et al., 2000a). 
The potential importance of neurotrophic factors for the development of therapeutic agents against neurodegenerative disorders and brain injury makes it vital to understand their structure, function and signaling mechanisms and may allow the design and engineering of analogs with desired pharmacological properties (Kazim and Khalid Iqbal, 2016).

Artemin (ARTN) is a member of the glial cell line-derived neurotrophic factor family ligands (GFLs) which includes three other members: glial cell line-derived neurotrophic factor (GDNF), neurturin (NRTN), and persephin (PSPN) (Baloh et al., 1998b; Airaksinen and Saarma, 2002). GFLs affect the generation, survival, and growth of neurons in different CNS neuronal populations, including midbrain dopaminergic neurons, central motor neurons, and noradrenergic neurons (Airaksinen and Saarma, 2002). Similar to GDNF, ARTN is a potential neuroprotective agent as it promotes the survival of dopaminergic neurons in vitro (Rosenblad et al., 2000; Sariola and Saarma, 2003). ARTN plays a role in pathogenesis and could be a target to improve the treatment of psychiatric disorders such as depression. ARTN plasma levels are reduced in patients with major depressive disorder (Pallanti et al., 2014), and intracerebroventricular administration of ARTN shows dose-dependent antidepressant effects in mice, potentially via modulation of neuronal plasticity (Mannelli et al., 2011).

Artemin also plays a role in the generation and survival of sympathetic neurons at different stages of development (Anders et al., 2001; Honma et al., 2002). Gfro3-/- mice exhibited severe defects in the superior cervical ganglion (SCG), causing lack of sympathetic innervation in the upper eyelid and submandibular salivary gland (Nishino et al., 1999).

Systemic treatment with ARTN normalizes morphological and neurochemical properties of injured small dorsal root ganglion neurons and mitigates behavioral symptoms associated with neuropathic pain in surgically and chemically induced nerve injury models (Gardell et al., 2003; Bennett et al., 2006; Wang et al., 2008; Wong et al., 2015). Results from Phase 1 clinical trials (Rolan et al., 2015; Okkerse et al., 2016) further support the application of ARTN for treatment of peripheral nerve injury and attenuation of neuropathic pain. A recent Phase 2 trial (SPRINT) that evaluated the safety and efficacy of intravenous ARTN (neublastin, BG00010) in reducing pain in patients with lumbosacral radiculopathy showed evidence of pain relief, particularly at the lowest dose of ARTN (Backonja et al., 2017).

Artemin is a homodimer in which the two monomers are assembled in a "tail-to-head" fashion and are stabilized by an inter-chain disulfide bond (Airaksinen et al., 1999; Baloh et al., 2000a; Scott and Ibañéz, 2001).

GDNF family ligands signal through a multicomponent receptor system consisting of the RET receptor tyrosine kinase, common for all GFL members, and a ligand-specific glycosylphosphatidylinositol-anchored co-receptor GFL receptor $\alpha\left(\mathrm{GFR} \alpha_{1-4}\right)$ (Airaksinen and Saarma, 2002) that determines the ligand-binding specificity of the GFR $\alpha$-RET complex. ARTN specifically binds to GFR $\alpha 3$ (Yan et al., 2003), which is mainly expressed in the cerebellum (Masure et al., 1998). Although ARTN prefers to bind with the GFR $\alpha 3$-RET complex, it can also bind with the GFR $\alpha 1-R E T$ complex (Baloh et al., 1998b).
Additional "cross-talk" between GFLs and GFR $\alpha$ s has been described (Baloh et al., 1998a; Trupp et al., 1998; Airaksinen et al., 1999). Assembling of the GFL-GFR $\alpha$-RET complex triggers the dimerization of RET, leading to autophosphorylation of specific tyrosine residues in its intracellular domain and subsequent activation of different intracellular signal cascades. These include Akt, MAPK-Erk, JNK, and Src, which are involved in regulation of cell survival, differentiation, proliferation, migration, hemotaxis, morphogenesis, neurite outgrowth, and synaptic plasticity (Airaksinen and Saarma, 2002). Adding to the complexity of the system, RET is expressed in three main isoforms, of which the 3 '-end alternatively spliced RET9 and RET51 are the most highly expressed and well-studied (Richardson et al., 2012). Moreover, RET9- and RET51associated signal complexes and pathways of degradation are markedly different. The third isoform of RET, RET43, was described in humans (Carter et al., 2001). Recently, two additional functional isoforms of RET that lack either exon 3 or exons 3-5 were described in CNS (Gabreski et al., 2016).

Two alternative receptors for GDNF are described, i.e., neural adhesion molecule (NCAM) (Paratcha et al., 2003) and heparan sulfate proteoglycan syndecan-3 (Bespalov et al., 2011), which is a transmembrane proteoglycan that binds to the GFL dimer with very high affinity (Cik et al., 2000; Leppänen et al., 2004), contrary to the GFR $\alpha$-RET receptor complex.

Analysis of expression profile in different brain domains, including central neocortex, cingulate cortex, basal ganglia, and hippocampus, showed that GFR $\alpha$ s are more widely expressed than RET (Trupp et al., 1997; Yu et al., 1998), suggesting that GFLs may signal independently of RET. This was corroborated by the finding that NCAM and GFR $\alpha 1$ function as an alternative signaling receptor for GDNF in hippocampal and cortical neurons (Paratcha et al., 2003). However, there have so far been no reports that NCAM and GFR $\alpha 3$ can act as an alternative receptor complex for ARTN.

We designed and characterized a putative ARTN mimetic peptide corresponding to the heel region, named artefin, and investigated its survival and neuritogenic potential in primary neuronal cultures, interaction with receptor complex GFR $\alpha$-RET, and intracellular signaling pathways involved in the action of ARTN. We found that ARTN bound directly to NCAM, and that both NCAM expression and activation of downstream signaling partners were required for ARTN-induced neurite outgrowth, thereby indicating that NCAM is an alternative receptor for ARTN.

\section{MATERIALS AND METHODS}

\section{Mimetic Peptides}

The sequence of ARTN-derived peptide artefin, RSPHDLSLASLLGAG (Supplementary Figure S1), corresponds to amino acids 166-180 of human ARTN (UniProt D3DPX9). The artefin peptide, its scrambled (LPLSSLRGHSGADAL) and reversed (GAGLLSALSLDHPSR) versions, and the control P2-d peptide (GRILARGEINFK) were synthesized as a tetramer composed of four monomers coupled to a lysine backbone 
using the solid-phase Fmoc protection chemistry (Schafer-N, Copenhagen, Denmark). The peptide purity was $\geq 80 \%$ as estimated by high-performance liquid chromatography. The recombinant human ARTN was purchased from R\&D Systems (Abingdon, United Kingdom).

\section{Circular Dichroism Spectroscopy}

Circular dichroism (CD) spectra were measured over the range 190-250 nm using a Jasco J-810 spectropolarimeter in cells with path length $1 \mathrm{~mm}$ at room temperature. The peptide

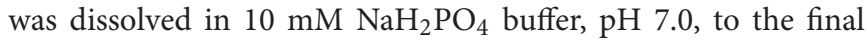
concentration $10 \mu \mathrm{M}$. Data were recorded at a scan speed of $20 \mathrm{~nm} / \mathrm{min}$ with 10 repeat scans accumulated to obtain the final average spectra. Following the buffer subtraction, the observed ellipticity $\theta$ (mdeg) was converted to mean residue ellipticity [ $\theta$ ] $\left(\mathrm{deg} \mathrm{cm}^{2} / \mathrm{dmol}\right)$ using the following relationship $[\theta]=100 \theta$ $/(l c n)$ where ' $l$ ' is path length in centimeters, ' $c$ ' is the millimolar concentration, and ' $n$ ' is the number of residues in the peptide.

\section{Cell Cultures}

\section{Primary Cultures of Cerebellar Granule Neurons}

Cerebellar granule neurons (CGNs) were prepared from 7day-old Wistar rat pups (Charles River Laboratories, Sulzfeld, Germany) as previously described (Schousboe et al., 1989). Briefly, pups were decapitated, and the cerebellum was removed and cleared from blood vessels and meninges in ice-cold modified Krebs-Ringer buffer. The cerebellum was dissociated by chopping and trypsinization. Cells were washed in Krebs-Ringer buffer containing DNAse I (Sigma, St. Louis, MO, United States) and soybean trypsin inhibitor (Sigma) to stop trypsinization, and the remaining tissue pieces were pelleted by centrifugation. Cells were then washed in Krebs-Ringer buffer containing $\mathrm{Ca}^{2+}$ and $\mathrm{Mg}^{2+}$ and re-suspended in appropriate Neurobasal ${ }^{\mathrm{TM}}$ medium (Invitrogen, Taastrup, Denmark) with supplements depending on the experiment.

\section{Cell Lines}

The pheochromocytoma cell line PC12-E2 (gift from Dr. Klaus Seedorf, Hagedorn Research Institute, Gentofte Municipality, Denmark) was propagated in Dulbecco's modified Eagle's medium (DMEM) supplemented with $5 \%(\mathrm{v} / \mathrm{v})$ fetal calf serum (FCS), 10\% (v/v) horse serum (HS), 1\% (v/v) glutamax, $100 \mathrm{U} / \mathrm{ml}$ penicillin, and $100 \mu \mathrm{g} / \mathrm{ml}$ streptomycin. Cells were grown at $37^{\circ} \mathrm{C}$ in a humidified atmosphere containing $5 \% \mathrm{CO}_{2}$.

\section{Survival Assay}

Cerebellar granule neurons were re-suspended in Neurobasal ${ }^{\mathrm{TM}}$ A medium supplemented with $2 \%(\mathrm{v} / \mathrm{v})$ B27 (Invitrogen, Taastrup, Denmark), 0.5\% (v/v) glutamax, $100 \mathrm{U} / \mathrm{ml}$ penicillin, $100 \mu \mathrm{g} / \mathrm{ml}$ streptomycin, and $40 \mathrm{mM} \mathrm{KCl}$, and seeded at a density of $1 \times 10^{5}$ cells/well in 8 -well LabTek Permanox chamber slides (Nunc, Roskilde, Denmark) coated with polyL-lysine $(10 \mu \mathrm{g} / \mathrm{ml})$. To avoid proliferation of non-neuronal cells, cytosine- $\beta$-D-arabinofuranoside (Sigma) was added to cells $24 \mathrm{~h}$ after plating. CGNs were allowed to differentiate for 7 days in vitro (DIV) in the presence of $40 \mathrm{mM} \mathrm{KCl}$ before being induced to undergo apoptosis by changing the medium to one containing only $5 \mathrm{mM} \mathrm{KCl}$ (apoptotic medium) (D’Mello et al., 1993). At 7 DIV, cells were washed and stimulated with serially diluted ARTN or artefin diluted in the apoptotic medium. Three different controls were included; (1) cells grown in medium containing $40 \mathrm{mM} \mathrm{KCl}$ served as a positive control; (2) cells grown in medium containing $5 \mathrm{mM} \mathrm{KCl}$ served as a negative control; (3) cells grown in medium containing $5 \mathrm{mM} \mathrm{KCl}$ supplemented with $50 \mathrm{ng} / \mathrm{ml}$ insulin growth factor-1 (IGF-1) (Life Technology), a known antiapoptotic factor for CGNs in this setup (Galli et al., 1995). After $48 \mathrm{~h}$ following the induction of apoptosis, cells were fixated in $4 \%$ formaldehyde for $30 \mathrm{~min}$, and nuclear morphology was visualized with Hoechst 33258 staining (Invitrogen, Taastrup, Denmark) (Figure 2A). Images of cells were obtained using a Nikon Diaphot 200 fluorescent microscope equipped with a Nikon Plan $40 \times$ objective (Nikon, Tokyo, Japan) and coupled to a black-white video camera. Images of at least 1000 cells/well in different fields of view were analyzed, and the percentage of viable neurons was estimated as the ratio of live cells (non-pyknotic cells with dispersed chromatin) to the total number of neurons.

\section{Neurite Outgrowth Assay}

Cerebellar granule neurons CGNs were re-suspended in Neurobasal ${ }^{\mathrm{TM}}$ medium supplemented with $2 \%(\mathrm{v} / \mathrm{v}) \mathrm{B} 27,0.5 \%$ (v/v) glutamax, $100 \mathrm{U} / \mathrm{ml}$ penicillin, $100 \mu \mathrm{g} / \mathrm{ml}$ streptomycin, $0.4 \%$ (w/v) BSA, and $20 \mathrm{mM}$ HEPES and were seeded in 8-well LabTek Permanox chamber slides (Nunc) at a density of $1 \times 10^{4}$ cells $/ \mathrm{cm}^{2}$. Various concentrations of ARTN, artefin, scrambled artefin, or reversed artefin were added to neurons immediately after seeding. For the RET inhibition assay, the inhibitory goat anti-mouse RET antibody (4.1 $\mu \mathrm{g} / \mathrm{ml}$; R\&D systems, Abingdon, United Kingdom) or control goat IgG $(4.1 \mu \mathrm{g} / \mathrm{ml}$; Santa Cruz Biotechnology, Dallas, TX, United States) were added to neurons $1 \mathrm{~h}$ before stimulation with ARTN $(0.042 \mathrm{nM})$ or artefin $(4.2 \mu \mathrm{M})$. For the competition assay between growth factor and mimetic peptide, a combination of ARTN $(2.1 \mathrm{nM})$ and artefin $(4.2 \mu \mathrm{M})$ was added to the cells immediately after seeding. To inhibit Fibroblast growth factor receptor (FGFR) pharmacologically, inhibitor of FGFR, SU5402 (Sigma), was added to the growth medium in serial dilutions of 20,40 , and $80 \mu \mathrm{M}$ immediately after plating of CGNs, followed by addition of either P2$\mathrm{d}(8 \mu \mathrm{g} / \mathrm{ml})$, ARTN $(0.21 \mathrm{nM})$, or artefin $(1.4 \mu \mathrm{M}) 1 \mathrm{~h}$ after the plating.

To evaluate the involvement of NCAM and RET in neurite outgrowth induced by either ARTN or artefin, CGNs $\left(3 \times 10^{6}\right.$ per transfection) were transfected with $3 \mu \mathrm{g}$ DNA using a Nucleofector $^{\mathrm{TM}} 2 \mathrm{~b}$ device and a Rat Neuron Nucleofector Kit (Amaxa, Inc., Gaithersburg, MD, United States). A kinasedeleted dominant negative RET insert was obtained by direct PCR using a commercially available clone (IRAKp961P02132Q; RZPD, Berlin, Germany) encoding full-length mouse RET coding sequence 586-3807 nt. as template. The upper primer ATATATGCTAGCTATGGCGAAAGCGACGTCCGG contained a NheI restriction site and Kozak sequence, and the lower primer ATATATGCGGCCGCTTATTTTTCGAACTGCGGGTGGCTC 


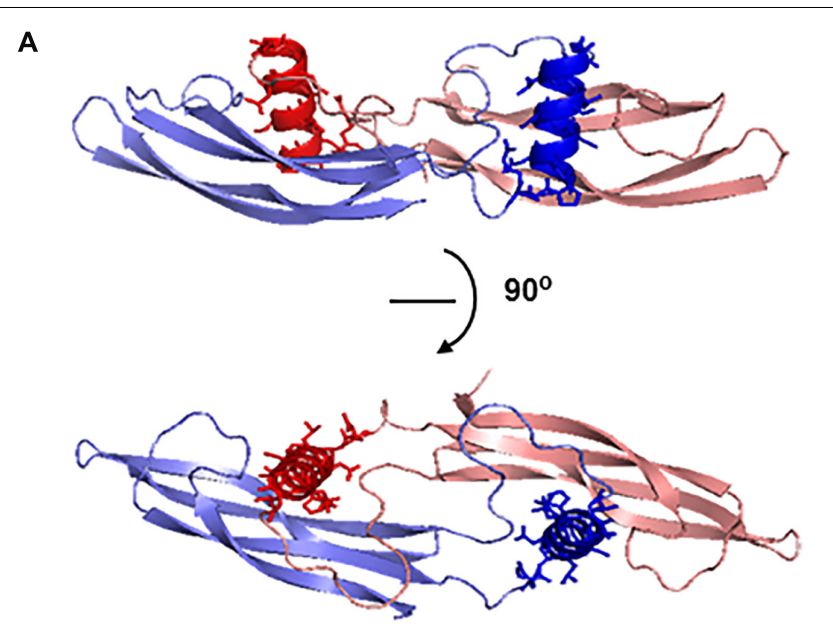

B

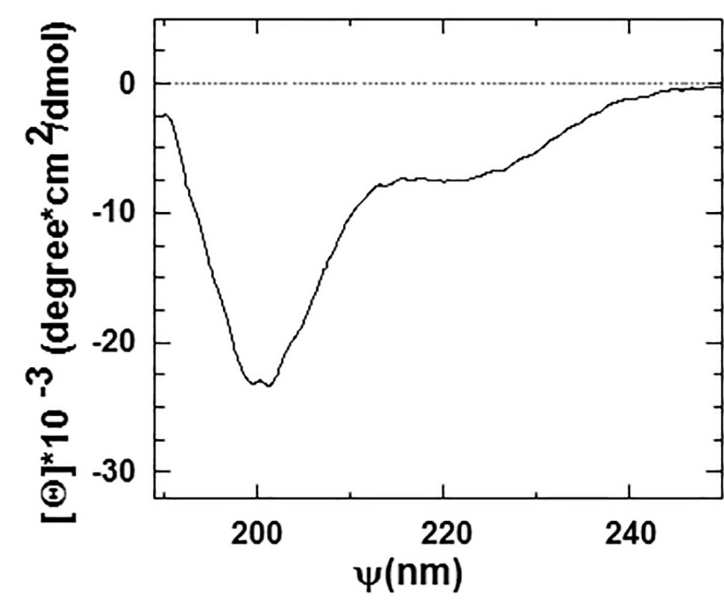

FIGURE 1 | (A) Ribbon structure of the ARTN dimer indicating the position of artefin sequence (shown in dark red and dark blue) corresponding to the heel region of the molecules. (B) Circular dichroism (CD) spectra of the artefin tetrameric peptide. The minimum at $208 \mathrm{~nm}$, a shoulder at $222 \mathrm{~nm}$, and a pick at $193 \mathrm{~nm}$ indicate that artefin keeps the a-helical conformation in solution.

CAAGCGCTAACCTGGTTCTCCGTGGAATCCAG encoded Streptag II and NotI restriction sites. The dominant negative RET insert and the pcDNA5/FRT expression vector containing the Flp-In system were cut with NheI and NotI restriction enzymes, purified, ligated using the Rapid DNA Ligation Kit (Roche, Basel, Switzerland), and transfected into One Shot TOP10 E. coli (Invitrogen, Taastrup, Denmark). E. coli colonies containing the dominant negative RET insert were identified by PCR, and one insert-positive colony was used for plasmid purification. The identity of the purified plasmid was verified by restriction cutting and sequencing of the insert. For NCAM knock down, we used a pENTR vector containing the shRNA expression cassette for NCAM knock down (Hansen et al., 2007). An empty vector was used as a control. To identify transfected neurons, all transfections were performed as co-transfections with $0.5 \mu \mathrm{g}$ pEGFP-N1, an expression vector encoding the enhanced variant of green fluorescent protein (GFP; Clontech, Palo Alto, CA, United States). Transfected CGNs were seeded in
Neurobasal $^{\mathrm{TM}}$-A medium supplemented with 2\% (v/v) B27, 5\% (v/v) FCS, and $2 \mathrm{mM}$ Glutamax at a density of $1 \times 10^{5}$ cells $/ \mathrm{cm}^{2}$.

To inhibit FGFR function in neurons, CGNs $\left(3 \times 10^{6}\right)$ were transfected with either a vector encoding a dominant negative version of FGFR1 (dnFGFR), lacking the kinase domain (Saffell et al., 1997; Enevoldsen et al., 2012) or the corresponding empty control vector using Amaxa Nucleofection (Lonza, Cologne, Germany). The pEGFP-N1 was added as a transfection control as previously described (Enevoldsen et al., 2012). The transfected cells were plated at a density of $5 \times 10^{5}$ cells/well in transfection medium [Neurobasal ${ }^{\mathrm{TM}}$-A medium supplemented with $2 \%(\mathrm{v} / \mathrm{v})$ $\mathrm{B} 27,2 \%(\mathrm{v} / \mathrm{v})$ horse serum, and $2 \mathrm{mM}$ glutamax].

To estimate neurite outgrowth, neurons were fixated $24 \mathrm{~h}$ after stimulation and stained with rabbit anti-growth-associatedprotein-43 (GAP-43) antibody (Chemicon International, Inc., Temecula, CA, United States) or anti-GFP antibody (for transfection experiment) overnight at $4^{\circ} \mathrm{C}$ followed by incubation with secondary Alexa-conjugated goat anti-rabbit antibodies (Invitrogen, Taastrup, Denmark). In case of experiments with plasmid transfection, the transfection efficiency was ca. $20 \%$ of total cells and the neurite outgrowth was evaluated only in GFPpositive, i.e., transfected, cells. For representative pictures, cells were additionally co-stained with Hoechst 33258.

Computer-assisted fluorescent microscopy was performed using a Nikon Diaphot 300 inverted microscope (Nikon) equipped with a Nikon Plan $20 \times$ objective and coupled to a video camera (Grundig Electronics, Germany). For each condition in each experiment, including the experiment with transfections, images of approximately 200 cells were recorded in systematic series of fields of view, and neurite outgrowth was quantified using a stereological approach as previously described (Rønn et al., 2000).

\section{Surface Plasmon Resonance (SPR) Analysis}

The binding analysis was performed on a Biacore ${ }^{\mathrm{TM}} 2000$ instrument (GE Healthcare, Hillerød, Denmark) at $25^{\circ} \mathrm{C}$ using HBS-EP (10 mM HEPES pH 7.4, $150 \mathrm{mM} \mathrm{NaCl,} 3 \mathrm{mM}$ EDTA, and $0.005 \% \mathrm{v} / \mathrm{v}$ Surfactant P20) as running buffer. ARTN and artefin were immobilized on a CM 4 sensor chip at a flow rate of $5 \mu \mathrm{l} / \mathrm{min}$ using amine coupling kit (GE Healthcare). The chip was activated with $35 \mu$ l activation solution containing $N$-hydroxysuccinimide (NHS) and $N$-ethyl$N^{\prime}$-(dimethylaminopropyl)-carbodiimide (EDC). Approximately $35 \mu l 2.1 \mathrm{nM}$ ARTN in $10 \mathrm{mM}$ sodium acetate $(\mathrm{pH} 5.0)$ or $35 \mu \mathrm{l} 78 \mu \mathrm{M}$ artefin in $10 \mathrm{mM}$ sodium acetate ( $\mathrm{pH} 5.0$ ) were injected over the chip yielding immobilization levels of approximately 2300 and $1600 \mathrm{RU}$, respectively. The chip was then deactivated with $35 \mu \mathrm{l} 1.0 \mathrm{M}$ ethanolamine. For binding analysis, serially diluted recombinant human GFR $\alpha 3 / F c$ (R\&D Systems, Abingdon, United Kingdom) and recombinant rat NCAM Ig13, produced as described previously (Soroka et al., 2003), were diluted in HBS-EP buffer and injected over the chip at a flow rate of $20 \mu \mathrm{l} / \mathrm{min}$. Regeneration was performed with $150 \mathrm{mM}$ $\mathrm{NaCl}$ containing $12.5 \mathrm{mM} \mathrm{NaOH}$ (for GFR $\alpha 3$ ) or $2 \mathrm{M} \mathrm{NaCl}$ (for Ig1-3). In reverse binding experiments, GFRa1/Fc and GFRa2/Fc 


\section{A}

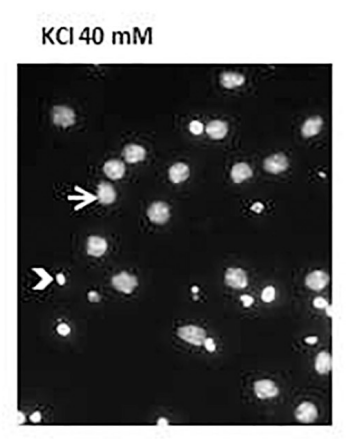

$\mathrm{KCl} 5 \mathrm{mM}$

$\mathrm{KCl} 5 \mathrm{mM}+1 \mathrm{GF}-1,50 \mathrm{ng} / \mathrm{ml}$
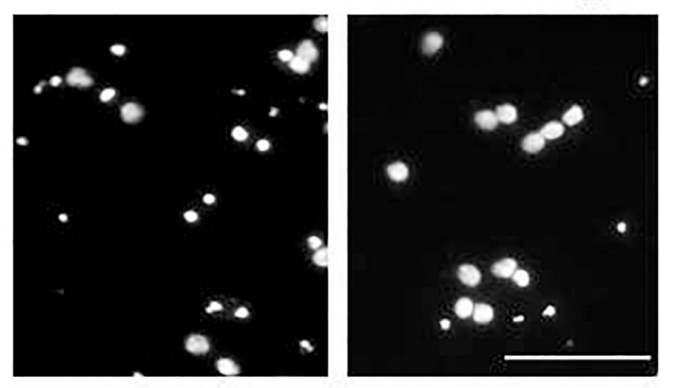

B

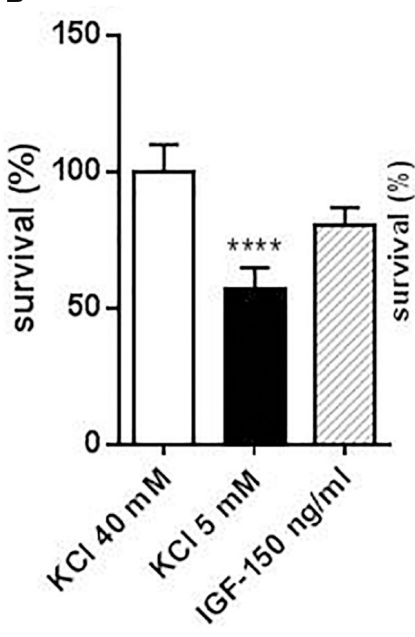

C

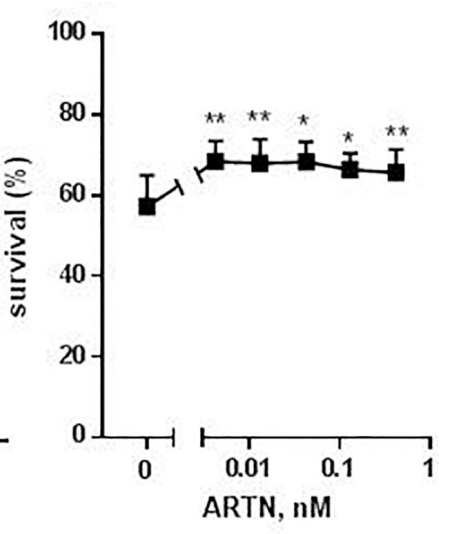

D

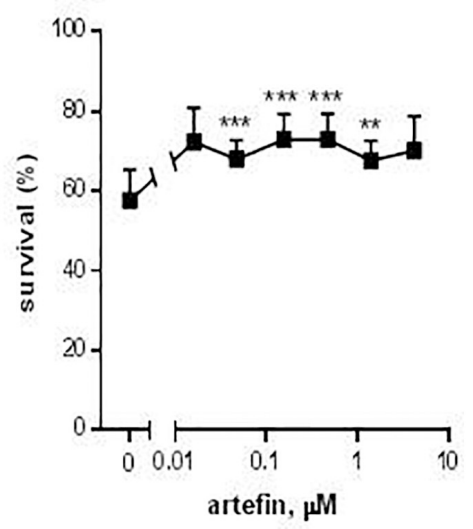

FIGURE 2 | Effect of ARTN and artefin on survival of cerebellar granular neurons (CGNs) induced to undergo apoptosis. CGNs were differentiated for 7 days in the presence of $40 \mathrm{mM} \mathrm{KCl}$ before apoptosis was induced by potassium withdrawal. (A) Nuclear morphology of CGNs after Hoechst 33258 staining. The arrow shows the intact nuclei with dispersed chromatin and arrowhead - picnotic nuclei with condense chromatin. Scale bar: $100 \mu \mathrm{m}$. Cells were grown for $48 \mathrm{~h}$ in media, containing $40 \mathrm{mM} \mathrm{KCl}$, apoptotic medium $(5 \mathrm{mM} \mathrm{KCl}$ ) or apoptotic medium supplemented with $50 \mathrm{ng} / \mathrm{ml}$ IGF-1 (positive control) (B), serially diluted ARTN (C), or artefin (D). Each experiment was performed in the presence of the three controls ( $40 \mathrm{mM} \mathrm{KCl}, 5 \mathrm{mM} \mathrm{KCl}$, and $5 \mathrm{mM} \mathrm{KCl}$ plus IGF-1), and the survival effect of the growth factor and the peptide was compared to its own apoptotic control $(5 \mathrm{mM} \mathrm{KCl})$. Results from the five experiments are expressed as percentage of $40 \mathrm{mM} \mathrm{KCl}$ control set at $100 \%$ and presented as mean \pm SEM. The anti-apoptotic effect of ARTN and artefin was tested using Student's paired $t$-test, where $* p<0.05$; ${ }^{* *} p<0.01 ;{ }^{* * *} p<0.001 ;{ }^{* * *} p<0.0001$.

(0.113 $\mu \mathrm{M}$; R\&D systems) were immobilized on CM 4 chip and first the corresponding positive control proteins, GDNF (5.07 $\mathrm{nM}$ ) and NRTN (6.2 nM), were injected. The binding of ARTN (6.2 nM) and artefin (15.6 $\mu \mathrm{M})$ were performed simultaneously. The curves corresponding to the differences between the binding to the immobilized protein and the binding to a blank well were used for analysis. Curves were further referenced by subtracting appropriate control curves obtained by injecting HBS-EP buffer alone. Curves were analyzed by nonlinear curve fitting using a 1:1 interaction model or steady-state affinity analysis applying the software package BIAevaluation v. 4.1 (GE Healthcare).

\section{RET Phosphorylation Assay}

Phosphorylation of RET was assayed in PC12-E2 cells. Cells were seeded at a density of $7 \times 10^{4}$ cells $/ \mathrm{cm}^{2}$ in $6 \mathrm{~cm}$ cell culture dishes (Nunc) and grown for $24 \mathrm{~h}$. Cells were then grown in starvation medium (growth media with FCS switched to $1 \%$ ) for $4 \mathrm{~h}$ before being stimulated with recombinant human ARTN (2.1 nM) or artefin (12.64 $\mu \mathrm{M})$ for $10 \mathrm{~min}$. Non-stimulated cells served as a control. Cell lysates were separated by SDS-polyacrylamide gel electrophoresis (SDSPAGE) and transferred to an Immobilon-P membrane (Millipore, Billerica, MA, United States). Membranes were stained with mouse anti-phosphotyrosine antibody (BD Transduction Lab, New York City, NY, United States; 1:500) or RET (goat antimouse antibody, R\&D systems, 1:500), followed by incubation with HRP-conjugated anti-mouse IgG. Immune complexes were visualized by chemiluminescence (SuperSignal West Dura Extended Duration Substrate, Pierce Biotechnology, Rockford, IL, United States) using a GeneGnome (Syngene, Cambridge, United Kingdom). Membranes were stripped for immune complexes and re-probed using goat anti-RET antibody (R\&D systems; 1:500) followed by incubation with HRP-conjugated 
rabbit anti-goat IgG. RET phosphorylation was determined as the ratio between phosphorylated and total RET.

\section{Statistical Analysis}

Results are expressed as mean values \pm standard error of the mean (SEM). The data are given as percentage of control, the control being set to $100 \%$. Statistical evaluation of data was performed using either paired $t$-test or one-way analysis of variance (ANOVA) for repeated measurements followed by Dunnett's or Tukey's post-tests. Evaluation was done using the software package GraphPad Prism v.4.02 (GraphPad Software, Inc., San Diego, CA, United States) or FIG-P version 2.98 (Biosoft, Cambridge, United Kingdom). Asterisks indicate the significance levels as follows: ${ }^{*} p<0.05 ;{ }^{* *} p<0.01$; ${ }^{* * *} p<0.001 ;{ }^{* * *} p<0.0001$.

\section{RESULTS}

\section{ARTN and an ARTN-Derived Peptide, Artefin, Promote the Survival of CGNs}

The ARTN monomer is composed of two $\beta$-sheet fingers, a cystine-knot core motif, and an $\alpha$-helical heel region (Figure 1A). Finger 1 comprises two long continuous antiparallel $\beta$ strands, whereas finger 2 has interruptions in the middle, resulting in five relatively short $\beta$-strands in the $\beta$-sheet. Within the dimer, the helix in the heel region of one ARTN monomer contacts the finger region of another monomer with its helical axis nearly perpendicular to the $\beta$-strands [43, 44, and Figure 1A].

We focused on the $\alpha$-helical heel region of ARTN, where a number of side chains are exposed outside of the dimer and thus available for potential interactions with other molecules. We designed a peptide covering this part of the molecule and named it artefin (Figure 1A). Far-ultraviolet CD spectroscopy of artefin peptide showed a negative band at $208 \mathrm{~nm}$, a shoulder at $222 \mathrm{~nm}$, and a positive band at $193 \mathrm{~nm}$ (Figure 1B), indicating that a-helix confirmation is dominant for the artefin peptide in solution.

The neuroprotective function of ARTN is well-known, and ARTN promotes the survival of various central and peripheral neuronal populations (Anders et al., 2001; Enomoto et al., 2001; Honma et al., 2002). Therefore, to investigate the putative mimetic abilities of artefin, we tested whether artefin promotes neuronal survival in vitro using CGNs, which are known to express GFR $\alpha 1$, GFR $\alpha 3$, and RET (Nosrat et al., 1997; Widenfalk et al., 1997; Masure et al., 1998). As CGNs require depolarizing concentrations of $\mathrm{KCl}$ for survival and differentiating in vitro (D’Mello et al., 1993; Widenfalk et al., 1997), the change to the apoptotic medium with low potassium led to a significant decrease in the proportion of live cells (Figures 2A,B, black column vs. white column). Treatment with $50 \mathrm{ng} / \mathrm{ml}$ IGF-1, which is a known pro-survival factor for CGNs both in vitro (Galli et al., 1995) and in vivo (Chrysis et al., 2001), significantly increased the number of CGNs rescued from the apoptosis induced by the potassium withdrawal ( $p<0.0001$; Figures 2A,B).

Addition of serially diluted ARTN to apoptotic medium promoted the survival of CGNs in culture in a dose-dependent manner (Figure 2C). The maximal neuroprotective effect (68.3\% of control) was obtained with $0.004 \mathrm{nM} \mathrm{ARTN}$. We subsequently investigated the effect of artefin and found that serially diluted peptide significantly promoted neuronal survival (Figure 2D).

The maximum level of neuronal survival was $72.95 \%$ of the controls and was obtained with $0.156 \mu \mathrm{M}$ artefin. These data show that artefin can mimic the neuroprotective function of ARTN, indicating that artefin may be a functional ARTN mimetic. Of note, ARTN and artefin have similar efficacy (neuroprotective effect), but the peptide has a lower potency as its effect is in the range of $\mu \mathrm{M}$ concentrations while ARTN works in the $\mathrm{nM}$ range.

\section{ARTN and Artefin Induce Neurite Outgrowth in CGNs}

Neuritogenesis is a key process for proper development of the nervous system, and neurotrophic factors are known to modulate neurite outgrowth (Yan et al., 2003). ARTN has been shown to induce neurite outgrowth from a number of neuronal populations, e.g., dorsal root and superior cervical and lumbar sympathetic ganglia (Anders et al., 2001; Enomoto et al., 2001; Honma et al., 2002; Yan et al., 2003). Therefore, we aimed to investigate whether artefin could also mimic neurite outgrowth induced by ARTN. ARTN induced neurite outgrowth from primary CGNs in a bell-shaped dose-response manner (Figure 3A), and the overall neuritogenic effect of ARTN was statistically significant $(F=5.069, p<0.01)$. The maximum level of neurite outgrowth was $210 \%$ of the controls and was obtained with $0.042 \mathrm{nM}$ ARTN (Figure 3F). Subsequent treatment with artefin, applied in a form of dendrimer, also induced neurite outgrowth in CGNs (Figure 3B) and was actually more effective (higher length of neurites) than ARTN. The overall neurite elongation effect of artefin was statistically significant $(F=9.723$, $p<0.0001)$, and the maximum effect $(404 \%$ of control) was obtained with $4.2 \mu \mathrm{M}$ of artefin (Figure 3F). In contrast, the artefin in monomer form did not demonstrate any significant neurite outgrowth in CGNs (Figures 3C,F).

To ensure the specificity of the mimetic effect of artefin, we tested the neurite outgrowth potential of a scrambled and a reversed versions of artefin (designed as tetramers) (Figure 3D). Artefin-treated neurons exhibited a statistically significant increase in neurite length when compared to the control condition $(p<0.01)$. In contrast, the level of neurite outgrowth was similar to control for neurons treated with either the scrambled or reversed version of the artefin peptides, thereby confirming the sequence-specific neurite outgrowth effect of artefin.

To further substantiate our finding, we tested whether artefin uses the same receptor complex as ARTN, i.e., whether a high, non-neuritogenic concentration of ARTN could impede the neurite outgrowth effect of artefin (Figure 3E). Neurite outgrowth in neurons treated with high concentration of ARTN alone was equivalent to that of the control condition, whereas neurons treated with artefin alone showed a significant increase in neurite outgrowth $(p<0.001)$. However, when neurons were co-incubated with artefin in the presence of ARTN, the neurite outgrowth effect of artefin was eliminated $(p<0.001$; 
A

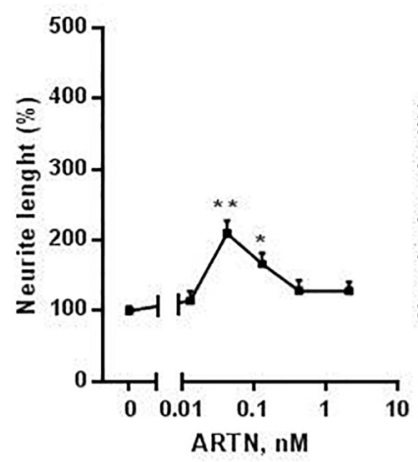

D

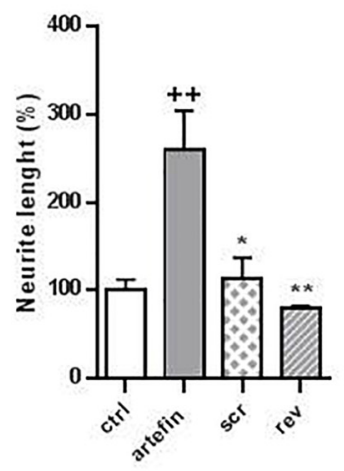

B

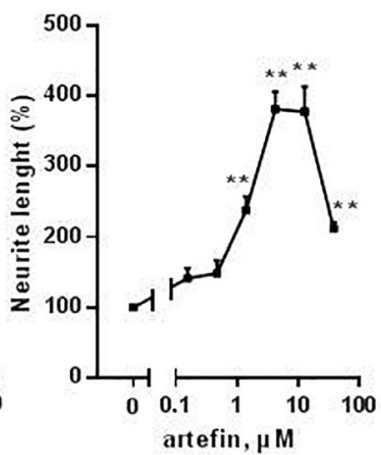

E

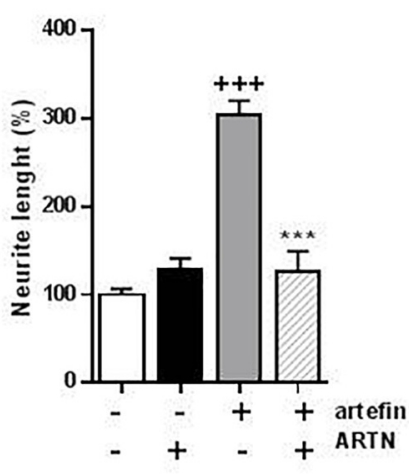

C

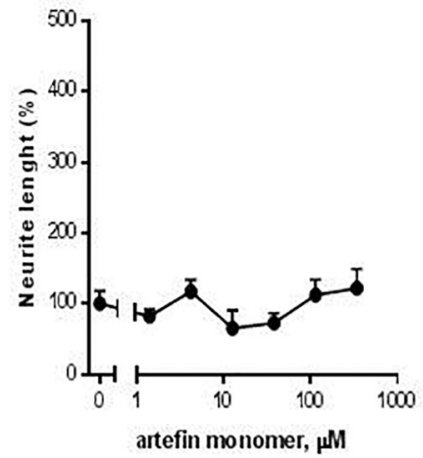

$\mathbf{F}$
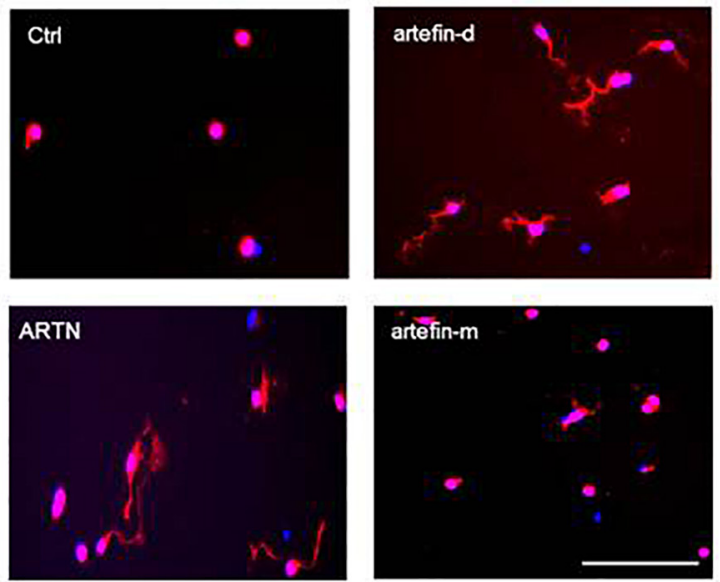

FIGURE 3 | Neurite outgrowth induced by ARTN (A), artefin-dendrimer (B), and artefin-monomer (C) in CGNs. Cells were stimulated with ARTN (0.013, 0.042, 0.13, 0.42 , and $2.1 \mathrm{nM})$ or artefin $(0.16,0.47,1.4,4.2,12.6$, and $37.9 \mu \mathrm{M})$ for $24 \mathrm{~h}$. For the unstimulated control, the absolute length of neurites was $11.47 \pm 1.5 \mu \mathrm{m}$. Results from four independent experiments are expressed as percentage of untreated control set to $100 \%$ and presented as mean \pm SEM. The mean neurite outgrowth lengths were compared using one-way ANOVA for repeated measurements. The effect of individual concentrations of ARTN and artefin was compared to control using one-way ANOVA with Dunnett's post-hoc test, ${ }^{*} p<0.05$; ${ }^{* *} p<0.01$. (D) Neuritogenic effect of artefin, scrambled and reverse peptides (tetramers). CGN neurons were treated with peptides in concentration of $4.2 \mu \mathrm{M}$ for $24 \mathrm{~h}$. The results are expressed as percentage of untreated control set to $100 \%$ and presented as mean \pm SEM. The neuritogenic effect was compared using Student's paired $t$-test where + indicates $p$-values for comparison to the negative control of untreated neurons, and ${ }^{*}$ indicates $p$-values for comparison to the positive control of neurons treated with artefin. ${ }^{++} p<0.01 ;{ }^{*} p<0.05$, ${ }^{* *} p<0.01$. (E) Inhibition effect of ARTN on neurite outgrowth, by competing with artefin. CGNs were grown for $24 \mathrm{~h}$ in the presence of none-neuritogenic concentration of ARTN ( $2.1 \mathrm{nM}$ ), artefin $(4.2 \mu \mathrm{M})$, or co-incubated with ARTN together with artefin in the same concentrations. Results are expressed as percentage of untreated control set at $100 \%$ and presented as mean \pm SEM. The neuritogenic effect was compared using Student's paired $t$-test, where + indicates $p$-values for comparison to the negative control and $*$ indicates $p$-values for comparison to neurons stimulated with artefin alone. ${ }^{+++} p<0.001 ;{ }^{* * *} p<0.001$. (F) Representative images of CGNs stimulated with ARTN (0.042 nM), artefin-dendrimeric (atrefin-d; $4.2 \mu \mathrm{M}$ ) and artefin-monomer (artefin-m; $4.2 \mu \mathrm{M})$ double-stained for GAP-43 (red) and Hoechst (blue). Scale bar: $100 \mu \mathrm{m}$.

Figure 3E), indicating that artefin and ARTN compete for the same receptor complex.

\section{ARTN and Artefin Bind to GFR $\alpha 3$}

We next investigated whether artefin directly binds to GFR $\alpha 3$ by surface plasmon resonance (SPR). To confirm the proper functioning of GFR $\alpha 3$, its known ligand, ARTN, was first used in binding experiments as a positive control. GFR $\alpha 3$ showed a clear concentration-dependent binding to ARTN (Figure 4A), and the affinity constant $K_{D}$ for the ligand-receptor interaction was in the low nanomolar range (Table 1).

GFR $\alpha 3$ also showed a clear, concentration-dependent binding to artefin (Figure 4B), and the affinity of the interaction was similar to that of the ARTN-GFR $\alpha 3$ interaction (Table 1). Moreover, similar to ARTN, which has previously been shown to interact with GFR $\alpha 1$ and GFR $\alpha 2$ (Scott and Ibañéz, 2001), artefin binds to GFR $\alpha 1$ and GFR $\alpha 2$, suggesting that artefin is a promiscuous binding epitope within ARTN sequence (Supplementary Figure S2).

\section{ARTN and Artefin Bind Directly to NCAM}

The involvement of NCAM in ARTN-induced effects has not been reported previously, although studies indicate that ARTNrelated GDNF can bind and signal through NCAM (Poteryaev et al., 1999; Trupp et al., 1999; Paratcha et al., 2003). We investigated whether NCAM can also be a functional receptor 


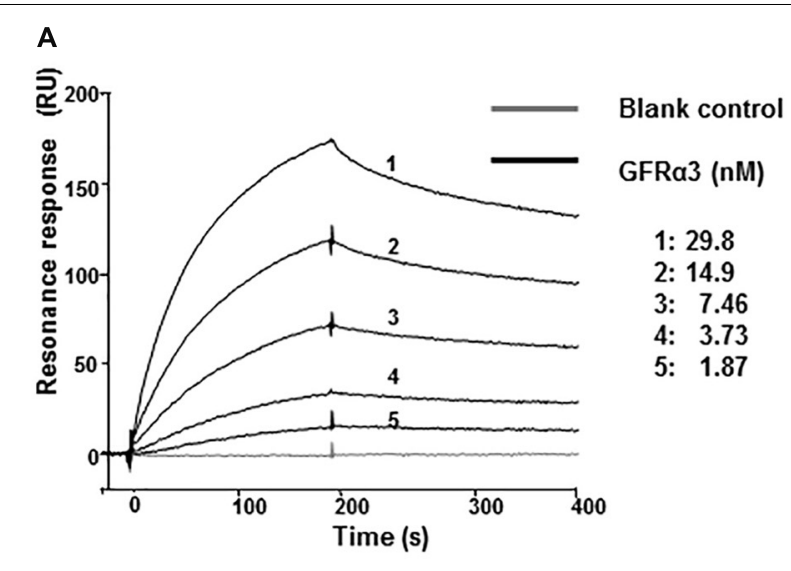

C

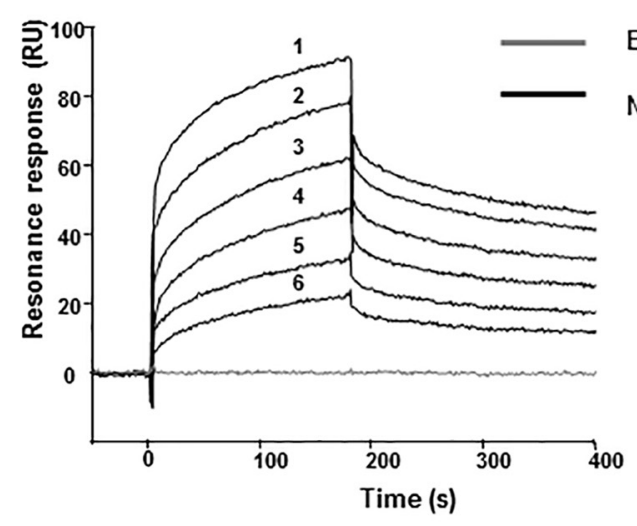

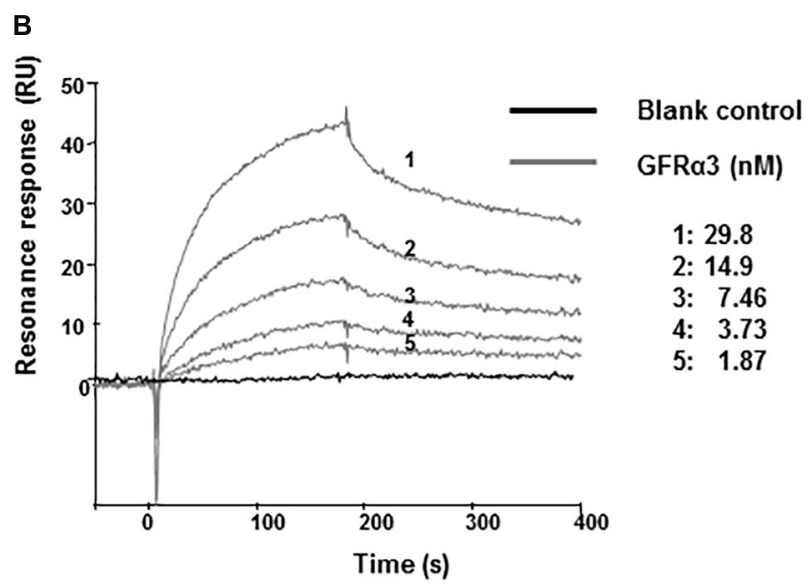

D

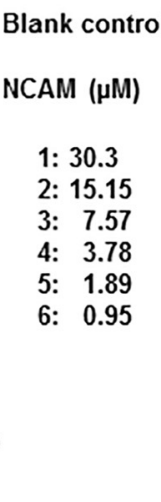

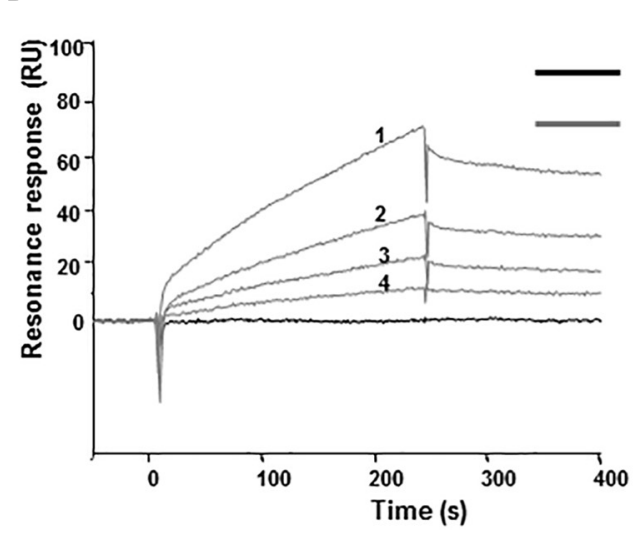

Blank control

NCAM $(\mu \mathrm{M})$

1: 15.15

2: 7.57

3: 3.78

4: 1.89

FIGURE 4 | Surface plasmon resonance (SPR) analysis of binding of immobilized ARTN or artefin to serially diluted recombinant human GFR $\alpha 3 / F c$ (A,B) and ARTN or artefin to serially diluted recombinant rat NCAM Ig1-3 domain (C,D). Immobilization levels of approximately 2300 RU for ARTN and 1600 RU for artefin were reached. Binding curves were analyzed by non-linear curve fitting using a 1:1 interaction model or steady-state affinity analysis applying the software package BIA evaluation v. 4.1 (GE Healthcare).

for ARTN. The recombinant NCAM protein comprising Ig13 domains, showed a clear, concentration-dependent binding to ARTN in SPR analysis (Figure 4C), indicating that there is a direct interaction between ARTN and NCAM. The $K_{D}$ for the interaction was in the low micromolar range (Table 1). These results indicate that ARTN can utilize NCAM as a receptor.

We have previously shown that the GDNF-binding site for NCAM is localized to the heel region and that gliafin, a GDNFderived peptide covering this region, binds to NCAM (Nielsen et al., 2009). As the tertiary structure of ARTN is similar to that of GDNF, we speculated that the artefin motif also contains a potential binding site for NCAM. As shown in Figure 4D, NCAM binds to artefin with the $K_{D}$ in the low micromolar range (Table 1), supporting the suggestion that artefin represents a binding site for NCAM within the heel region of ARTN.

\section{ARTN and Artefin Induce Phosphorylation of RET}

The binding of artefin to GFR $\alpha 3$ suggests that artefin may utilize a GFR $\alpha 3$-RET receptor complex, and we therefore tested if artefin could induce RET activation. Stimulation of PC12
TABLE 1 | Affinities for ligand-receptor interactions.

\begin{tabular}{lll}
\hline Injected protein & $\boldsymbol{A R T N}, \boldsymbol{K}_{\boldsymbol{D}}(\boldsymbol{M})$ & Artefin, $\boldsymbol{K}_{\boldsymbol{D}}(\boldsymbol{M})$ \\
\hline GFR $\alpha 3$ & $2.7 \times 10^{-9} \pm 2.8 \times 10^{-10}$ & $2.9 \times 10^{-9} \pm 6.5 \times 10^{-10}$ \\
NCAM & $1.3 \times 10^{-5} \pm 3.4 \times 10^{-6}$ & $2.8 \times 10^{-6} \pm 7.9 \times 10^{-7}$
\end{tabular}

Curves were analyzed by non-linear curve fitting using a Langmuir equation for 1:1 binding. The binding affinities were calculated from three independent experiments and are given as the mean \pm SEM.

cells with ARTN, serving as a positive control, led to a clear, statistically significant increase in RET phosphorylation $[\sim 600 \%$ compared to unstimulated control cultures (Figure 5)]. Artefin also significantly stimulated RET phosphorylation and had a similar efficiency to ARTN ( 500\%).

\section{ARTN- and Artefin-Induced Neurite Outgrowth Involves RET}

To investigate if the functional effects of artefin could be mediated via RET, we tested whether anti-RET antibodies would reduce artefin-induced neurite outgrowth. Neurons stimulated with 


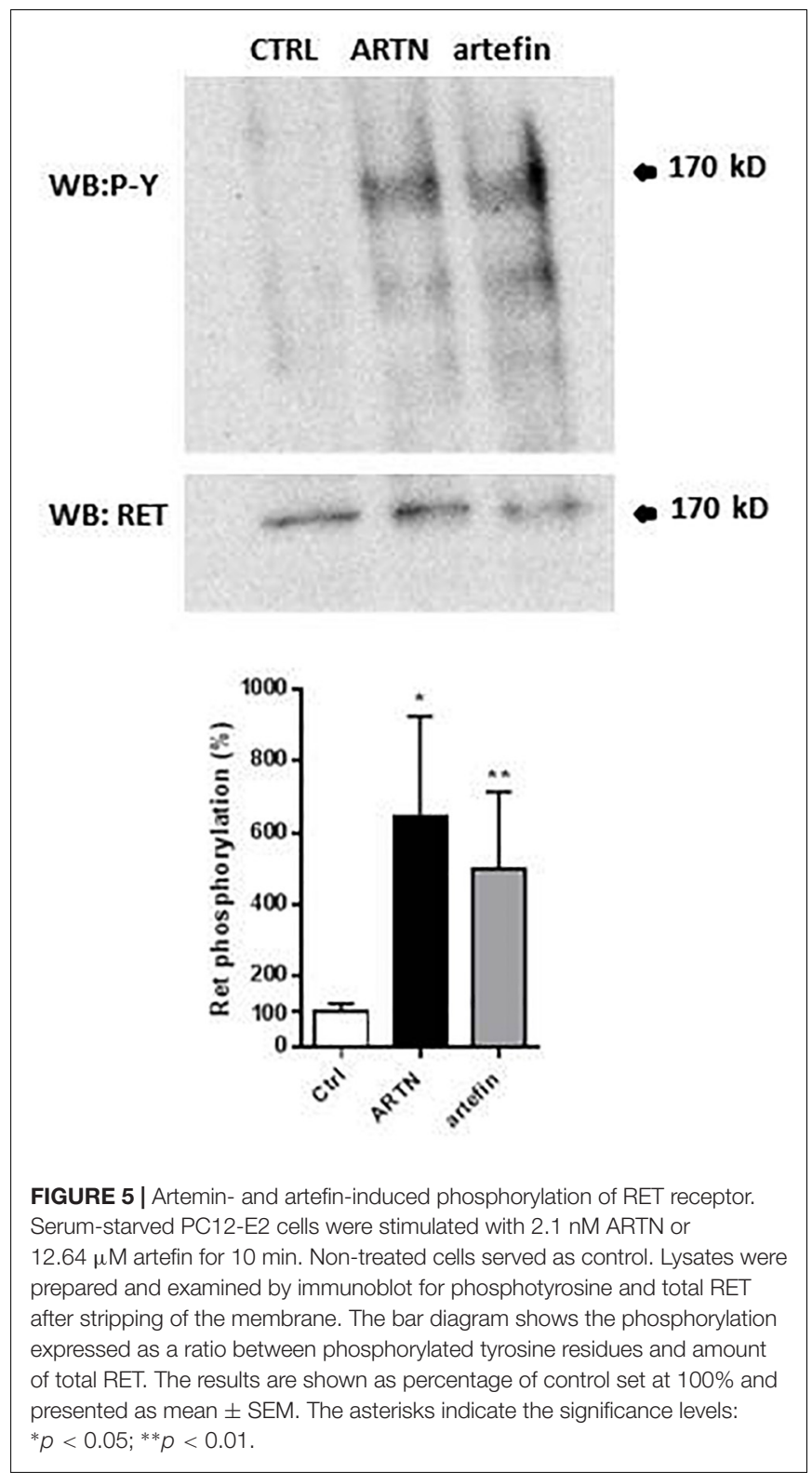

ARTN (Figure 6A) had a significantly higher level of neurite outgrowth than control cultures. Incubation with control IgG did not affect the ARTN-induced neurite outgrowth, but anti-RET antibodies completely abolished the neurite elongation effect of ARTN. When neurons were stimulated with artefin (Figure 6B), neurite outgrowth was, as expected, significantly increased when compared to the control $(p<0.01)$. Co-incubation with control IgG did not significantly alter the neuritogenic effect of artefin, whereas co-incubation with anti-RET antibodies led to a statistically significant reduction of artefin-induced neurite outgrowth ( $p<0.01$ versus artefin alone). Of note, the artefininduced neurite outgrowth was not completely abrogated by anti-RET antibody, and was still significantly different from unstimulated control ( $p<0.01$, Figure 6B). This shows that artefin-induced neurite outgrowth involves RET, similar to
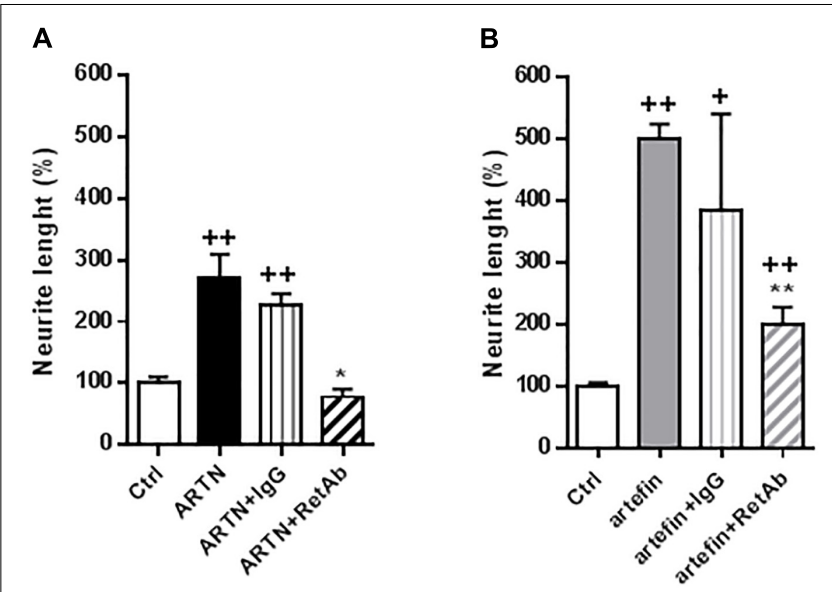

FIGURE 6 | Inhibition of ARTN-induced (A) and artefin-induced (B) neurite outgrowth in CGNs by anti-RET antibody. CGNs were pre-treated directly after plating for $1 \mathrm{~h}$ with anti-RET antibody or control IgG in concentrations $4.1 \mu \mathrm{g} / \mathrm{ml}$ before stimulating with ARTN $(0.042 \mathrm{nM})$ or artefin $(0.47 \mu \mathrm{M})$. Student's paired $t$-test was used for statistical evaluation of the results. + Indicates $p$-values for comparison of the neuritogenic effect of ARTN or artefin to the untreated control set at $100 \%$, while * shows $p$-values for the comparison of the inhibition effect of RET antibody to the control lgG. ${ }^{+} p<0.05 ;{ }^{++} p<0.01 ;{ }^{*} p<0.05 ;{ }^{* *} p<0.01$.

ARTN and suggesting that the neurite outgrowth effect of artefin may also be mediated via other receptors.

To further test the involvement of RET in artefin-induced neurite outgrowth, we transfected CGNs with a kinase-deleted dominant negative version of RET (dnRET) before stimulating neurons with ARTN or artefin. As a control, we stimulated transfected cells with the NCAM-derived P2-d-peptide; its sequence was derived from the NCAM homophilic binding site, and it is known to stimulate neurite outgrowth through NCAM (Jensen et al., 1999; Kasper et al., 2000; Soroka et al., 2003). Thus, P2-d-induced neurite outgrowth should not be affected by expression of dnRET. In line with this, we found that P2-d significantly increased the level of neurite outgrowth in mock-transfected neurons as well as in neurons transfected with the vector encoding $\operatorname{dnRET}(p<0.05$; Figure 7A). Neurite outgrowth was significantly increased by ARTN in mocktransfected neurons ( $p<0.05$ versus control), whereas ARTNinduced neurite outgrowth was abolished in neurons expressing dnRET ( $p<0.05$ versus ARTN alone; Figure 7A). Similarly to its parent protein, artefin significantly increased neurite outgrowth in mock-transfected neurons ( $p<0.01$ versus control), but this effect was abrogated in dnRET-transfected neurons $(p<0.01$ versus artefin alone; Figure 7A).

\section{ARTN- and Artefin-Induced Neurite Outgrowth Requires NCAM Expression}

Although the above data clearly indicate that RET is involved in ARTN- and artefin-induced neurite outgrowth, other receptors may also be involved. The observed binding of ARTN and artefin to NCAM (Figure 4) suggests that NCAM may mediate some of the effects of ARTN and artefin. To investigate this 

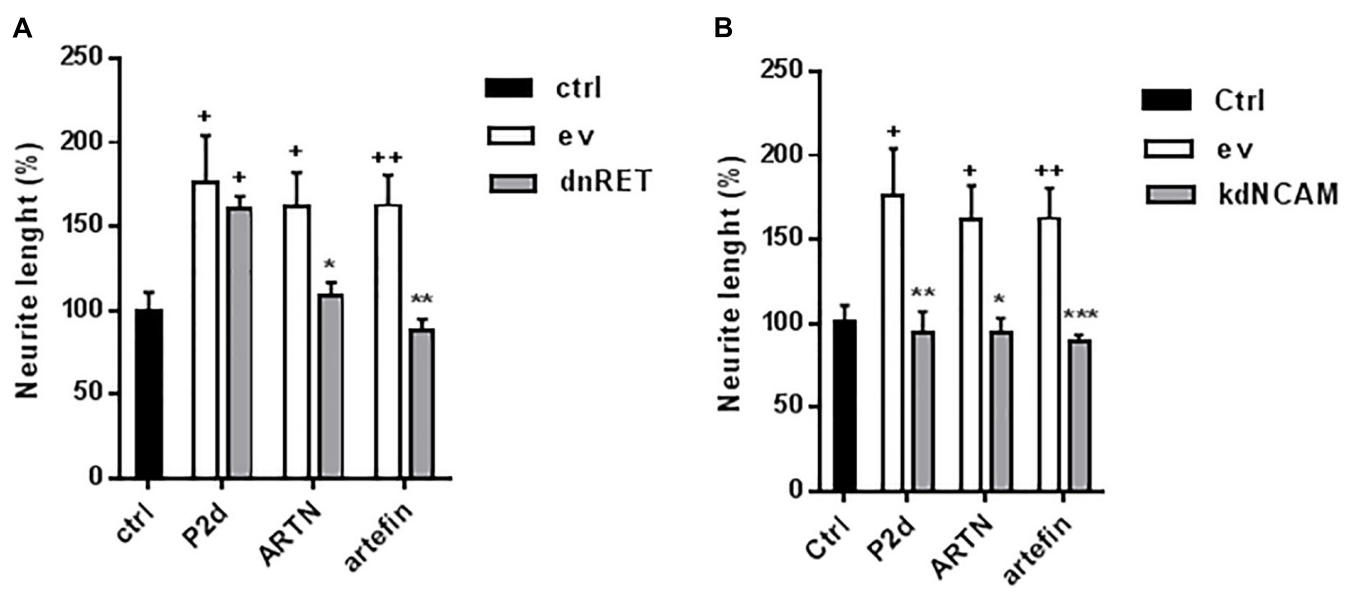

FIGURE 7 | Neuritogenic effect of ARTN and artefin in (A) dominant negative RET or (B) knock down NCAM-expressing CGNs. CGNs were transfected with empty vector (ev), dominant negative version of RET (dnRet), or shNCAM-encoding plasmid (kdNCAM) and stimulated with P2-d (8 $\mu \mathrm{g} / \mathrm{ml})$, ARTN (0.21 nM), and artefin $(1.4 \mu \mathrm{M})$ for $24 \mathrm{~h}$. The results are presented as percentage of control set at 100\%, and error bars indicate SEM. Student's paired $t$-test was used for evaluation. + Presents $p$-values for comparison of the neuritogenic effect of compounds to the untreated neurons, while * shows $p$-values for comparison to the positive control of CGNs transfected with empty vector. ${ }^{+} p<0.05 ;{ }^{++} p<0.01 ;{ }^{*} p<0.05 ;{ }^{* *} p<0.01 ;{ }^{* * *} p<0.001$.

possibility, we tested the neuritogenic potentials of ARTN and artefin in CGNs where NCAM expression was knocked down by transfection with NCAM shRNA, previously shown to be efficient (Hansen et al., 2007; Nielsen et al., 2009). In accordance, P2-d increased neurite outgrowth in mock-transfected neurons $(p<0.05)$, but this effect was eliminated in neurons transfected with NCAM shRNA $(p<0.01$; Figure 7B). Mock-transfected CGNs stimulated with ARTN showed a significantly higher level of neurite outgrowth compared to unstimulated controls $(p<0.05$; Figure 7B). However, down-regulation of NCAM expression completely abolished the neurite outgrowth effect of ARTN (Figure 7B), indicating that NCAM is involved in ARTN-induced neurite outgrowth. Similarly, artefin promoted the neurite outgrowth in mock-transfected neurons $(p<0.01)$, but this effect was abrogated in neurons where NCAM expression was knocked down ( $p<0.001$; Figure 7B). Thus, the neuritogenic effect of artefin, similar to the neuritogenic effect of ARTN, appears to be NCAM-dependent.

\section{ARTN- and Artefin-Induced Neurite Outgrowth Requires Activation of NCAM-Associated Signaling}

To further investigate the role of NCAM in ARTN- and artefin-induced neurite outgrowth, we examined if signaling downstream of NCAM was activated. NCAM does not possess any intracellular catalytic activity and utilizes other molecules, particularly the FGFR, for induction of intracellular signaling (Francavilla et al., 2009). We stimulated CGNs with ARTN or artefin in the absence or presence of a pharmaceutical FGFRinhibitor, SU5402, and observed the effect on neurite elongation.

Treatment with P2-d, a known activator of FGFR downstream of NCAM (Soroka et al., 2002) promoted neurite outgrowth in the absence of SU5402 ( $p<0.01)$, but co-incubation with $80 \mu \mathrm{M}$ SU5405 significantly attenuated this effect ( $p<0.01$; Figure 8A).
The neurite outgrowth effect of ARTN was completely abolished in the presence of serially diluted inhibitor $(p<0.01$; Figure 8B), indicating that ARTN-induced neurite outgrowth involves activation of the signaling downstream of NCAM.

Subsequent co-incubation of CGNs with SU5402 dosedependently inhibited the neurite outgrowth effect of artefin $(p<0.01$; Figure 8C). Therefore, artefin-induced neurite outgrowth seems to involve FGFR activation. To further confirm the role of NCAM-FGFR signaling, we transfected CGNs with dominant negative form of FGFR (Pankratova et al., 2016). The neurite outgrowth effect of ARTN and artefin was abolished in CGNs expressing dnFGFR (Figures 8D,E), confirming involvement of NCAM downstream signaling in the biological functions of ARTN and artefin.

\section{DISCUSSION}

The potential therapeutic use of neurotrophic factors have been intensively investigated ever since these factors were first identified (Rosenblad et al., 2000; Sariola and Saarma, 2003; Mannelli et al., 2011; Pallanti et al., 2014). For various reasons, however, neurotrophic factors have still not been successfully employed therapeutically. Mimetic compounds may overcome some of the obstacles connected with the use of neurotrophic factors, and in this study we applied a peptide-based approach to identify a new ARTN mimetic compound.

The study by Scott and Ibañéz (2001) demonstrated the cross-talk between GFLs and the members of GFR $\alpha$ s family. Their results showed that ARTN is the only GFL that can bind to all GFR $\alpha$, and the only one that can interact with GFR $\alpha 3$. According to solved structure of ARTN-GFR $\alpha 3$ complex, the extended epitopes located within Finger 1 and 2 regions of ARTN are responsible for its interaction to GFR $\alpha 3$ (Wang et al., 2006), whereas the heel region in the ARTN molecule 
A

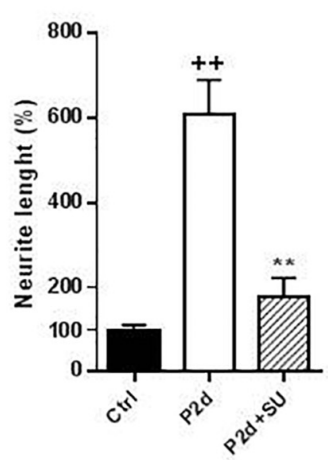

C

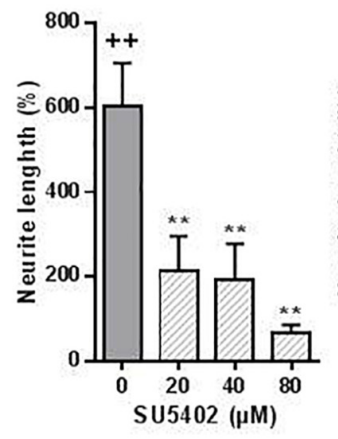

B

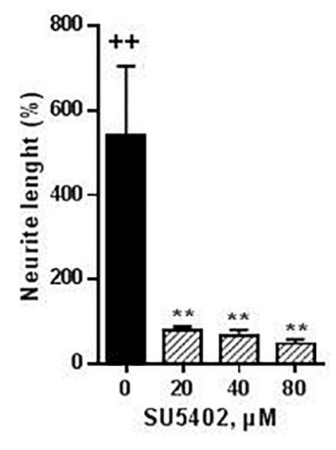

D

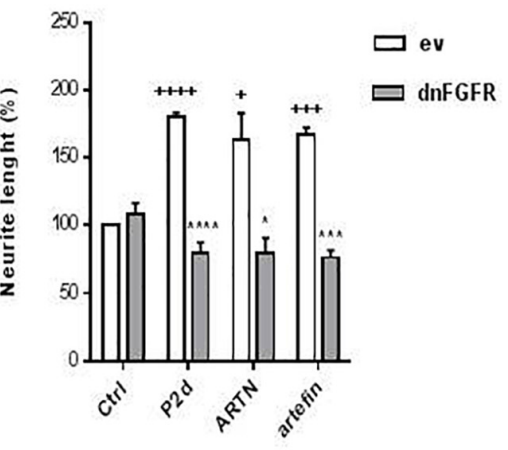

$\mathbf{E}$
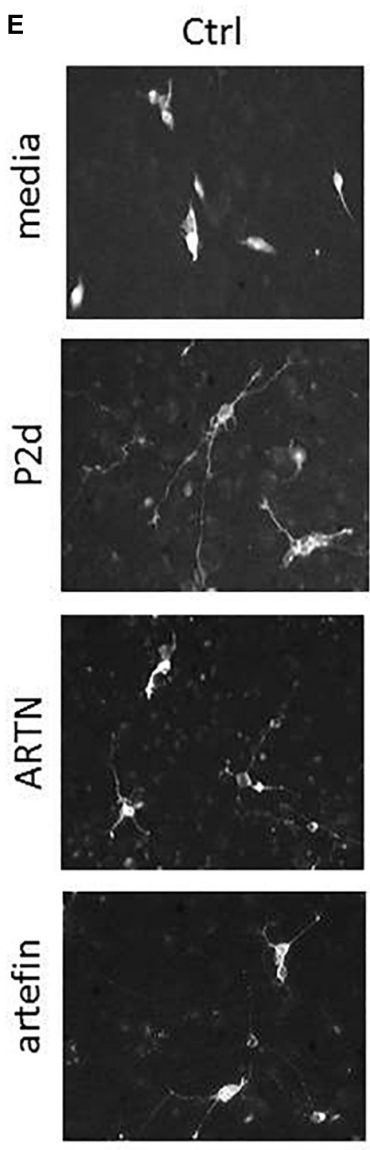
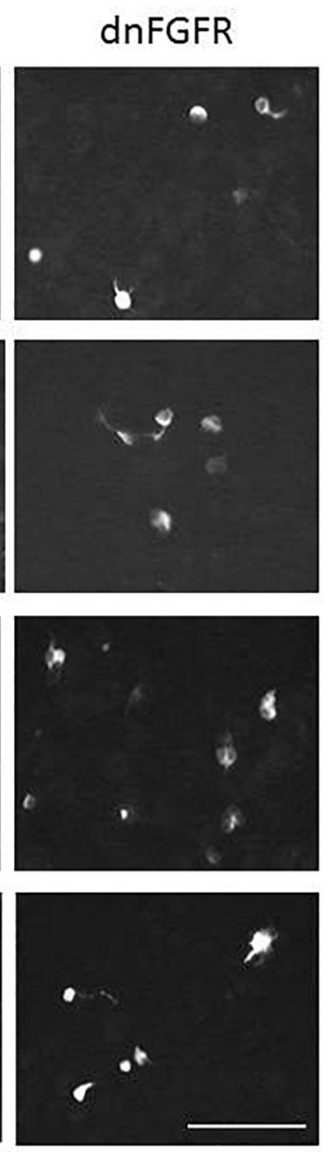

FIGURE 8 | Inhibition of ARTN- and artefin-induced neurite outgrowth in CGNs by FGFR-inhibitor SU5402. (A) Neurite outgrowth induced by P2-d peptide $(8 \mu \mathrm{g} / \mathrm{ml})$. + Presents $p$-values for comparison of the neuritogenic effect of the peptide to the untreated neurons, while * shows $p$-values for comparison to the positive control of CGNs stimulated with P2-d. (B) Inhibition of neurite outgrowth with serially diluted SU5402 (20, $40,80 \mu \mathrm{M})$ induced by ARTN (0.21 nM) (B) or artefin $(1.4 \mu \mathrm{M})$ (C). ${ }^{*}$ Shows $p$-values for comparison to the positive control of CGNs stimulated with ARTN or artefin. $++p<0.01$; ${ }^{* *} p<0.01$. (D) Inhibition of ARTN- and artefin-induced neuritogenic effect in dominant negative FGFR (dnFGFR) transfected CGNs. CGNs transfected with empty vector (ev) or dominant negative version of FGFR (dnFGFR) were plated and stimulated with P2-d (8 $\mu \mathrm{g} / \mathrm{ml})$, ARTN (0. $21 \mathrm{nM})$, or artefin (1.4 $\mu$ M) for $24 \mathrm{~h}$. The results are presented as percentage of control (CGNs transfected with empty vector) set at 100\%, and the error bars indicate SEM. Student's paired $t$-test was used for evaluation. +Presents $p$-values for comparison of the neuritogenic effect of compounds to the untreated neurons, while * shows $p$-values for comparison to the positive control of CGNs transfected with empty vector. ${ }^{+} p<0.05 ;{ }^{+++} p<0.001 ;{ }^{++++} p<0.0001 ;{ }^{*} p<0.05 ;{ }^{* * *} p<0.001 ;{ }^{* * * *} p<0.0001$. (E) Micrographs of neurite outgrowth of CGNs transfected with dnFGFR and incubated with media alone, P2-d, ARTN, and artefin. Scale bar: $100 \mu \mathrm{m}$.

is involved in formation and maintenance of the dimer (Baloh et al., 2000b; Wang et al., 2004). Surprisingly, our results show that artefin (which corresponds to the heel region of ARTN) binds to GFR $\alpha 3$ although with lower affinity compared to ARTN. Moreover, artefin has biological functions in terms of CGN survival and neuritogenesis, where GFR $\alpha 3$-RET system is centrally involved. The biological function of artefin is determined by the specific amino acid sequence (because peptides with scrambled and reverse sequences are not biologically active), and it forms a functional structure that can bind and activate the receptor complex. Further profound computational analysis, like molecular dynamic simulation, would be required to identify the binding site of artefin motif on GFR $\alpha 3$. The study of neurite outgrowth demonstrates that ARTN and artefin possess strong neuritogenic potential that only requires interaction between growth factor or peptide and the receptor on the surface of the cell membrane. When the parent protein and the peptide are placed in the same cellular system, ARTN competes with artefin for binding to receptor complex. This might explain the inhibitory effect of high none-neuritogenic concentrations of ARTN on the neurite outgrowth induced by artefin. Our results suggest that ARTN and artefin use the same signal system for promoting neurite outgrowth. Based on our results, we speculate that in addition to GFR $\alpha 3$-RET, NCAM-FGFR could be an alternative signaling system mediating the biological effects of ARTN/artefin.

It has been determined that GFR $\alpha$ receptors and RET do not show overlapping expression in different brain regions (Nosrat et al., 1997; Trupp et al., 1997; Yu et al., 1998). It has been suggested that GDNF binds NCAM and that this interaction is potentiated by GFR $\alpha 1$ (Paratcha et al., 2003). RETindependent GDNF signaling also acts in neurons expressing RET, as evidenced by Chao et al. (2003), who found that 
NCAM antibodies suppressed GDNF-induced survival and differentiation of midbrain dopaminergic neurons. Whether NCAM can be an alternative receptor for other GFLs has been established by Paratcha et al. (2003), who showed that other GFLs can bind to NCAM-containing complexes with their corresponding GFR $\alpha$. This suggests that ARTN and other GFLs may also utilize NCAM as a receptor. Notably, while GFLs do not bind to RET in the absence of their cognate GFR $\alpha$ (Anders et al., 2001), GDNF interacts directly with NCAM (Paratcha et al., 2003; Nielsen et al., 2009). NCAM could thus function as a signaling receptor for ARTN through a direct interaction between ARTN and NCAM. Although, we do not exclude the possibility, that knocking down of NCAM might affect the expression of other, yet unidentified, proteins potentially involved in mediation of ARTN effects, and thus the effect of NCAM knock-down on ARTN-induced neurite outgrowth might be indirect. To the best of our knowledge, there are no data confirming RETindependent ARTN-induced signaling. Our experiments show that inhibitory RET antibody can interfere with ARTN- and artefin-induced neurite outgrowth but does not completely block it, suggesting that some other receptor plays a role in ligandinduced neurite elongation. The absence of significant neurite outgrowth in NCAM knock down and dnFGFR CGNs further supports this suggestion (Figures 7B, 8D). Furthermore, we did not observe ARTN- and artefin-induced neurite outgrowth in neurons expressing dominant negative RET (Figure 7A), suggesting that both NCAM and RET are necessary for ARTNinduced signaling in CGNs. We speculate that the presence of NCAM in the signal system is always obligatory, but that it may be an alternative receptor for ARTN together with RET in the CGNs model.

Interestingly, artefin showed much stronger neurite outgrowth effect than ARTN. It is not unusual for a peptide mimetic, representing a small region of the molecule, to show a stronger efficacy than the whole molecule but to be less potent (as it needs a higher concentration to be effective) (Gjoerlund et al., 2012). The parent growth factor is typically more specific than small peptides and may contain spatially distant domains that can modulate the effect of the whole molecule. As artefin is synthesized as dendrimer consisting of four monomers coupled to a lysine backbone, one peptide can potentially bind four receptors simultaneously, this gives a stronger effect. Moreover, as we showed, this peptide keeps its $\alpha$-helical conformation in solution, thus perfectly mimicking the binding interface in the ARTN molecule (Figure 1B). We suggest that the secondary structure of artefin is important for the functioning of this peptide mimetic. Further studies are required to elucidate the possible mechanisms.

\section{CONCLUSION}

We confirmed that ARTN binds and signals through GFRa3-RET complex. We also found that ARTN bound directly to NCAM and that NCAM expression and activation of its downstream signaling partner, FGFR, were required for ARTN-induced neuritogenesis, thereby indicating that NCAM is an alternative receptor for ARTN. We propose that the heel region within the ARTN is a potential binding site of ARTN to NCAM. The peptide, derived from this heel region, artefin, has neuroprotective and neurite outgrowth effects similar to those of the parent growth factor, it is more effective but less potent. Both ARTN and artefin act through the same signal system(s), but the growth factor has a higher binding affinity. Further comprehensive study including mutagenesis is needed to identify the biological function(s) of heel region of ARTN.

\section{NOTE}

To the memory of Vladimir Berezin, deceased February 14, 2016.

\section{BIOETHICS}

Animals were treated in accordance with the Danish Animal Welfare Act, and the study was approved by the Department of Experimental Medicine at the University of Copenhagen.

\section{ETHICS STATEMENT}

All experiments were performed according to European Union legislation and with licenses from the Danish Animal Experiments Inspectorate. All animals were kept under standard conditions $\left(23^{\circ} \mathrm{C}, 50 \%\right.$ humidity, 12 -h light/dark cycle) with free access to food and water. The number of animals utilized in the respective experiments was kept to a minimum, and all work was conducted in a manner designed to cause the least harm and suffering to the animals.

\section{AUTHOR CONTRIBUTIONS}

MI, JN, IK, KG, SP, and EB conceived and designed the experiments. MI, JN, IK, KG, and SP performed the experiments. MI, JN, SP, EB, and TM analyzed the data and wrote the manuscript. EB and TM directed and supervised the project.

\section{FUNDING}

Financial support was gratefully acknowledged from P. A. Messerschmidt og Hustrus Fond, Direktør Jacob Madsen og Hustru Olga Madsens Fond, Torben og Alice Frimodts Fond, Beckett-fonden, Lundbeckfonden, and the European Union's 6th framework program PROMEMORIA (LSHM-CT-2005-512012).

\section{ACKNOWLEDGMENTS}

The authors wish to thank Lene Køhler and Peter S. Walmod for technical support and fruitful discussions. The authors thank to Clair Gudex, Department of Clinical Research, University of Southern Denmark, for proofreading the manuscript. 


\section{SUPPLEMENTARY MATERIAL}

The Supplementary Material for this article can be found online at: https://www.frontiersin.org/articles/10.3389/fnmol. 2019.00047/full\#supplementary-material

\section{REFERENCES}

Airaksinen, M. S., and Saarma, M. (2002). The GDNF family: signaling, biological functions and therapeutic value. Nat. Rev. Neurosci. 3, 383-394. doi: 10.1038/ nrn812

Airaksinen, M. S., Titievsky, A., and Saarma, M. (1999). GDNF family neurotrophic factor signaling: four masters, one servant? Mol. Cell Neurosci. 13, 313-325. doi: 10.1006/mcne.1999.0754

Anders, J., Kjær, S., and Ibañéz, C. F. (2001). Molecular modeling of the extracellular domain of the RET receptor tyrosine kinase reveals multiple cadherin-like domains and a calcium binding site. J. Biol. Chem. 276, 3580835817. doi: 10.1074/jbc.M104968200

Backonja, M., Williams, L., Miao, X., Katz, N., and Chen, C. (2017). Safety and efficacy of neublastin in painful lumbosacral radiculopathy: a randomized, double-blinded, placebo-controlled phase 2 trial using bayesian adaptive design (the SPRINT trial). Pain 158, 1802-1812. doi: 10.1097/j.pain.0000000000000983

Baloh, R. H., Enomoto, H., Johnson, E. M. Jr., and Milbrandt, J. (2000a). The GDNF family ligands and receptors - implications for neural development. Curr. Opin. Neurobiol. 10, 103-110. doi: 10.1016/S0959-4388(99)00048-3

Baloh, R. H., Tansey, M. G., Johnson, E. M. Jr., and Milbrandt, J. (2000b). Functional mapping of receptor specificity domains of glial cell line-derived neurotrophic factor (GDNF) family ligands and production of GFR $\alpha 1$ Retspecific agonists. J. Biol. Chem. 275, 3412-3420. doi: 10.1074/jbc.275.5.3412

Baloh, R. H., Gorodinsky, A., Golden, J. P., Tansey, M. G., Keck, C. L., Popescu, N. C., et al. (1998a). GFR $\alpha 3$ is an orphan member of the GDNF/neurturin/persephin receptor family. PNAS 95, 5801-5806.

Baloh, R. H., Tanesey, M. G., Lampe, P. A., Fahrner, T. J., Enomoto, H., Simburger, K. S., et al. (1998b). Artemin, a novel member of the GDNF ligand family, supports peripheral and central neurons and signals through the GFR $\alpha 3$-RET receptor complex. Neuron 21, 1291-1302. doi: 10.1016/S0896-6273(00)80649-2

Bennett, D. L., Boucher, T. J., Michael, G. J., Popat, R. J., Malcangio, M., Averill, S. A., et al. (2006). Artemin has potent neurotrophic actions on injured C-fibres. J. Peripher. Nerv. Syst. 11, 330-345. doi: 10.1111/j.1529-8027.2006.00106.x

Bespalov, M. M., Sidorova, Y. A., Tumova, S., Ahonen-Bishopp, A., Magalhães, A. C., Kulesskiy, E., et al. (2011). Heparan sulfate proteoglycan syndecan-3 is a novel receptor for GDNF, neurturin, and artemin. J. Cell Biol. 10, 153-169. doi: $10.1083 /$ jcb.201009136

Carter, M. T., Yome, J. L., Marcil, M. N., Martin, C. A., Vanhorne, J. B., and Mulligan, L. M. (2001). Conservation of RET proto-oncogene splicing variants and implications for RET isoform function. Cytog. Cell Genet. 95, 169-176. doi: $10.1159 / 000059341$

Chao, C. C., Ma, Y. L., Chu, K. Y., and Lee, E. H. (2003). Integrin av and NCAM mediate the effects of GDNF on DA neurons survival, outgrowth. DA turnover and motor activity in rats. Neurobiol. Aging 24, 105-116. doi: 10.1016/S01974580(02)00047-7

Chrysis, D., Calikoglu, A. S., Ye, P., and D'Ercole, A. J. (2001). Insulin-like growth factor-I overexpression attenuates cerebellar apoptosis by altering the expression of $\mathrm{Bcl}$ family proteins in a developmentally specific manner. J. Neurosci. 21, 1481-1489. doi: 10.1523/JNEUROSCI.21-05-01481.2001

Cik, M., Masure, S., Lesage, A. S., Van Der Linden, I., Van Gompel, P., Pangalos, M. N., et al. (2000). Binding of GDNF and neurturin to human GDNF family receptor alpha 1 and 2. Influence of cRET and cooperative interactions. J. Biol. Chem. 275, 27505-27512.

D'Mello, S. R., Galli, C., Ciotti, T., and Calissano, P. (1993). Induction of apoptosis in cerebellar granule neurons by low potassium: inhibition of death by insulinlike growth factor I and cAMP. PNAS 90, 10989-10993. doi: 10.1073/pnas.90. 23.10989

Enevoldsen, M. N., Kochoyan, A., Jurgenson, M., Jaako, K., Dmytriyeva, O., Walmod, P. S., et al. (2012). Neuroprotective and memory enhancing properties
FIGURE S1 | The scheme of dendrimeric artefin peptide. The figure shows a line-angle representation of the structure of the lysine backbone with four artefin sequences (RSPHDLSLALLGAG) attached.

FIGURE S2 | Surface plasmon resonance analysis of binding affinity of (A) artefin to GFR $\alpha 1$ and (B) artefin to GFR $\alpha 2$.

of a dual agonist of the FGF receptor and NCAM. Neurobiol. Dis. 48, 533-545. doi: 10.1016/j.nbd.2012.07.016

Enomoto, H., Crawford, P. A., Gorodinsky, A., Heuckeroth, R. O., Johnson, E. M. Jr., and Milbrandt, J. (2001). RET signaling is essential for migration, axonal growth and axon guidance of developing sympathetic neurons. Development 128, 3963-3974.

Francavilla, C., Cattaneo, P., Berezin, V., Bock, E., Ami, D., de Marco, A., et al. (2009). The binding of NCAM to FGFR1 induces a specific cellular response mediated by receptor trafficking. JCB 187, 1101-1116. doi: 10.1083/ jcb.200903030

Gabreski, N. A., Vaghasia, J. K., Novakova, S. S., McDonald, N. Q., and Pierchala, B. A. (2016). Exon Skipping in the ret gene encodes novel isoforms that differentially regulate ret protein signal transduction. J. Biol. Chem. 291, 1624916262. doi: 10.1074/jbc.M115.709675

Galli, C., Meucci, O., Scorziello, A., Werge, T. M., Calissano, P., and Schettini, G. (1995). Apoptosis in cerebellar granule cells is blocked by high $\mathrm{KCl}$, forskolin, and IGF-1 through distinct mechanisms of action: the involvement of intracellular calcium and RNA synthesis. J. Neurosci. 15, 1172-1179. doi: 10. 1523/JNEUROSCI.15-02-01172.1995

Gardell, L. R., Wang, R., Ehrenfels, C., Ossipov, M. H., Rossomando, A. J., Miller, S., et al. (2003). Multiple actions of systemic artemin in experimental neuropathy. Nat. Med. 9, 1383-1389. doi: 10.1038/nm944

Gjoerlund, M., Nielsen, J., Pankratova, S., Li, S., Korshunova, I., Bock, E. M., et al. (2012). Neuroligin-1 induces neurite outgrowth through interaction with neurexin- $1 \beta$ and activation of fibroblast growth factor receptor-1. FASEB J. 26, 4174-4186. doi: 10.1096/fj.11-202242

Hansen, R. K., Christensen, C., Korshunova, I., Kriebel, M., Burkarth, N., Kiselyov, V. V., et al. (2007). Identification of NCAM-binding peptides promoting neurite outgrowth via a heterotrimeric G-protein-coupled pathway. J. Neurochem. 103, 1396-1407. doi: 10.1111/j.1471-4159.2007.04894.x

Honma, J., Araki, T., Gianino, S., Bruce, A., Henckeroth, R., Yohanson, E., et al. (2002). Artemin is a vascular -derived neurotrophic factor for developing sympathetic neurons. Neuron 35, 267-282. doi: 10.1016/S0896-6273(02) 00774-2

Jensen, P. H., Soroka, V., Thomsen, N. K., Ralets, I., Berezin, V., Bock, E., et al. (1999). Structure and interactions of NCAM modules 1 and 2, basic elements in neural cell adhesion. Nat. Struc. Biol. 6, 486-493. doi: 10.1038/8292

Kasper, C., Rasmussen, H., Kastrup, J. S., Ikemizu, S., Jones, E. Y., Berezin, V., et al. (2000). Structural basis of cell-cell adhesion by NCAM. Nat. Struct. Biol. 7, 389-393. doi: 10.1038/75165

Kazim, S. F., and Khalid Iqbal, K. (2016). Neurotrophic factor smallmolecule mimetics mediated neuroregeneration and synaptic repair: emerging therapeutic modality for alzheimer's disease. Mol. Neurodegener. 11:50. doi: 10.1186/s13024-016-0119-y

Leppänen, V. M., Bespalov, M. M., Runeberg-Roos, P., Puurand, U., Merits, A., Saarma, M., et al. (2004). The structure of GFRalphal domain 3 reveals new insights into GDNF binding and RET activation. EMBO J. 23, 1452-1462. doi: 10.1038/sj.emboj.7600174

Mannelli, L. D. C., Vivoli, E., Salvicchi, A., Schiavone, N., Koverech, A., Messano, M., et al. (2011). Antidepressant-like effect of artemin in mice: a mechanism for acetyl-L-carnitine activity on depression. Psychopharmacology 218, 347-356. doi: 10.1007/s00213-011-2326-0

Masure, S., Cik, M., Pangalos, M. N., Bonaventure, P., Verhasselt, P., Lesage, A., et al. (1998). Molecular cloning expression and tissue distribution of glial-cellline-derived neurotrophic factor family receptor $\alpha-3$ (GFR $\alpha-3$ ). FEBS 251, 622-630.

Nielsen, J., Gotfryd, K., Li, S., Kulahin, N., Soroka, V., Rasmussen, K. K., et al. (2009). Role of glial cell line-derived neurotrophic factor (GDNF)-neural cell adhesion molecule (NCAM) interactions in induction of neurite outgrowth 
and identification of a binding site for NCAM in the heel region of GDNF. J. Neurosci. 29, 11360-11376. doi: 10.1523/JNEUROSCI.3239-09.2009

Nishino, J., Mochida, K., Ohfuji, Y., Shimazaki, T., Meno, C., Ohishi, S., et al. (1999). GFR alpha3, a component of the artemin receptor, is required for migration and survival of the superior cervical ganglion. Neuron 23, 725-736. doi: 10.1016/S0896-6273(01)80031-3

Nosrat, C. A., Tomac, A., Hoffer, B. J., and Olson, L. (1997). Cellular and developmental patterns of expression of Ret and glial cell line derived neurotrophic factor receptor mRNAs. Exp. Brain Res. 115, 410-422. doi: 10. 1007/PL00005711

Okkerse, P., Hay, J. L., Versage, E., Tang, Y., Galluppi, G., Ravina, B., et al. (2016). Pharmacokinetics and pharmacodynamics of multiple doses of BG00010, a neurotrophic factor with anti-hyperalgesic effects, in patients with sciatica. $B r$. J. Clin. Pharmacol. 82, 108-117. doi: 10.1111/bcp.12941

Pallanti, S., Tofani, T., Zanardelli, M., Di Cesare Mannelli, L., and Ghelardini, C. (2014). BDNF and artemin are increased in drug-naïve non-depressed GAD patients: preliminary data. Int. J. Psychiatr. Clin. Pract. 18, 255-260. doi: 10. 3109/13651501.2014.940051

Pankratova, S., Bjornsdottir, H., Christensen, C., Zhang, L., Li, S., Dmytriyeva, O., et al. (2016). Immunomodulator CD200 Promotes neurotrophic activity by interacting with and activating the fibroblast growth factor receptor. Mol. Neurobiol. 53, 584-594. doi: 10.1007/s12035-014-9037-6

Paratcha, G., Ledda, F., and Ibañéz, C. F. (2003). The neural cell adhesion molecule NCAM is an alternative signaling receptor for GDNF family ligands. Cell 113, 867-879. doi: 10.1016/S0092-8674(03)00435-5

Poteryaev, D., Tytievsky, A., Sun, Y. F., Thomas-Crusells, J., Lindahl, M., Arumae, U., et al. (1999). GDNF triggers a novel ret-independent Src kinase famil-coupled signaling via a GPI-linked GDNF receptor $\alpha 1$. FEBS Lett. 463, 63-66. doi: 10.1016/S0014-5793(99)01590-2

Richardson, D. S., Rodrigues, D. M., Hyndman, B. D., Crupi, M. J., Nicolescu, A. C., and Mulligan, L. M. (2012). Alternative splicing results in RET isoforms with distinct trafficking properties. Mol. Biol. Cell 23, 3838-3850. doi: 10.1091/mbc. E12-02-0114

Rolan, P. E., O’Neill, G., Versage, E., Rana, J., Tang, Y., Galluppi, G., et al. (2015). First-in-human, double-blind, placebo-controlled, randomized, doseescalation study of BG00010, a glial cell line-derived neurotrophic factor family member, in subjects with unilateral sciatica. PLoS One 10:e0125034. doi: 10. 1371/journal.pone. 0125034

Rønn, L. C., Ralets, I., Hartz, B. P., Bech, M., Berezin, A., Berezin, V., et al. (2000). simple procedure for quantification of neurite outgrowth based on stereological principles. J. Neurosci. Methods 31, 25-32. doi: 10.1016/S0165-0270(00)00228-4

Rosenblad, C., Gronborg, M., Hansen, C., Blom, N., Meyer, M., Johansen, J., et al. (2000). In vivo protection of nigral dopamine neurons by lenti viral gene transfer of the novel GDNF-family member neublastin/artemin. Mol. Cell Neurosci. 15, 199-214. doi: 10.1006/mcne.1999.0817

Saffell, J. L., Williams, E. J., Mason, I. J., Walsh, F. S., and Doherty, P. (1997). Expression of a dominant negative FGF receptor inhibits axonal growth and FGF receptor phosphorylation stimulated by CAMs. Neuron 18, 231-242. doi: 10.1016/S0896-6273(00)80264-0

Sariola, H., and Saarma, M. (2003). Novel functions and signaling pathways for GDNF. J. Cell Sci. 116, 3855-3862. doi: 10.1242/jcs.00786

Schousboe, A., Meier, E., Drejer, J., and Hertz, L. (1989). "Preparation of primary cultures of mouse cerebellar granule neurons," in A Dissection and Tissue Culture Manual of the Nervous System, eds A. Shahar, J. de Vellis, A. Vernadakis, and B. Haber (New York,NY: Alan R. Liss), 203-206.

Scott, R. P., and Ibañéz, C. F. (2001). Determinants of ligand binding specificity in the glial cell line-derived neurotrophic factor family receptor alpha S. J. Biol. Chem. 12, 1450-1458. doi: 10.1074/jbc.M006157200

Soroka, V., Kiryushko, D., Novitskaya, V., Ronn, L. C., Poulsen, F. M., Holm, A., et al. (2002). Induction of neuronal differentiation by a peptide corresponding to the homophilic binding site of the second Ig module of the neural cell adhesion molecule. J. Biol. Chem. 277, 676-624. doi: 10.1074/jbc.M109694200

Soroka, V., Kolkova, K., Kastrup, J. S., Diedrich, K., Breed, J., Kiselyov, V. V., et al. (2003). Structure and interactions of NCAM Ig1-2-3 suggest a novel zipper mechanism for homophilic adhesion. Structure 11, 1291-1301. doi: 10.1016/j. str.2003.09.006

Trupp, M., Belluardo, N., Funakoshi, H., and Ibañéz, C. F. (1997). Complementary and overlapping expression of glial cell line-derived neurotrophic factor (GDNF), c-ret proto-oncogene, and GDNF receptor- $\alpha$ indicates multiple mechanisms of trophic actions in the adult rat CNS. J. Neurosci. 17, 3554-3567. doi: 10.1523/JNEUROSCI.17-10-03554.1997

Trupp, M., Raynoschek, C., Belluardo, N., and Ibañéz, C. F. (1998). Multiple GPIanchored receptors control GDNF-dependent and independent activation of the c-Ret tyrosine kinase. Mol. Cell. Neurosci. 11, 47-63. doi: 10.1006/mcne. 1998.0667

Trupp, M., Scott, R., Whittemore, S. R., and Ibañéz, C. F. (1999). Ret-dependent and independent mechanisms of glial cell-line derived neurotrophic factor signaling in neuronal cells. J. Biol. Chem. 274, 20885-20894. doi: 10.1074/jbc. 274.30.20885

Wang, L. M., Zhang, Q., Zhu, W., He, C., Lu, C. L., Ding, D. F., et al. (2004). Identification of the key amino acids of glial cell line-derived neurotrophic factor receptor $\alpha 1$ involved in its biological function. J. Biol. Chem. 279, 109-116. doi: 10.1074/jbc.M306287200

Wang, R., King, T., Ossipov, M. H., Rossomando, A. J., Vanderah, T. W., Harvey, P., et al. (2008). Persistent restoration of sensory function by immediate or delayed systemic artemin after dorsal root injury. Nat. Neurosci. 11, 488-496. doi: 10. 1038/nn2069

Wang, X., Baloh, R. H., Milbrandt, J., and Garcia, K. C. (2006). Structure of artemin complexed with its receptor GFRalpha3: convergent recognition of glial cell line-derived neurotrophic factors. Structure 14, 1083-1092. doi: 10.1016/j.str. 2006.05.010

Widenfalk, J., Nosrat, C., Tomac, A., Wesphal, H., Hoffer, B., and Olson, L. (1997). Neurturin and glial cell line- derived neurotrophic factor receptor- $\beta$ (GDNFR$\beta$ ), novel proteins related to GDNF and GDNFR- $\beta$ with specific cellular patterns of expression suggesting roles in the developing and adult nervous system and in peripheral organs. J. Neurosci. 17, 8506-8519. doi: 10.1523/JNEUROSCI.1721-08506.1997

Wong, A. W., Yeung, J., Payne, S. C., Keast, J. R., and Osborne, P. B. (2015). Neurite outgrowth in normal and injured primary sensory neurons reveals different regulation by nerve growth factor (NGF) and artemin. Mol. Cell. Neurosci. 65, 125-134. doi: 10.1016/j.mcn.2015.03.004

Yan, H., Newgreen, D. F., and Young, H. M. (2003). Developmental changes in neurite outgrowth responses of dorsal root and sympathetic ganglia to GDNF, neurturin and artemin. Dev. Dyn. 227, 395-401. doi: 10.1002/dvdy.10294

Yu, T., Scully, S., Yu, Y., Fox, G. M., Jing, S., and Zhou, R. (1998). Expression of GDNF family receptor components during development: implications in the mechanisms of interaction. J. Neurosci. 18, 4684-4696. doi: 10.1523/ JNEUROSCI.18-12-04684.1998

Conflict of Interest Statement: The authors declare that the research was conducted in the absence of any commercial or financial relationships that could be construed as a potential conflict of interest.

Copyright (๑) 2019 Ilieva, Nielsen, Korshunova, Gotfryd, Bock, Pankratova and Michel. This is an open-access article distributed under the terms of the Creative Commons Attribution License (CC BY). The use, distribution or reproduction in other forums is permitted, provided the original author(s) and the copyright owner(s) are credited and that the original publication in this journal is cited, in accordance with accepted academic practice. No use, distribution or reproduction is permitted which does not comply with these terms. 